\title{
Precursores de la revolución mundial
}

\author{
Marco Antonio Samaniego López*
}

Recibido: 3 de agosto de 2020

Dictaminado: 17 de octubre de 2020

Aceptado: 20 de noviembre de 2020

\section{RESUMEN}

En Regeneración, los anarquistas del Partido Liberal Mexicano, de 1911 a 1918, llamaron al proletariado estadounidense y europeo a realizar una revolución mundial que terminara con el capitalismo y toda forma de autoridad. Su pretensión era formar conscientes que expropiaran todos los medios de producción, por lo que permanecieron en Los Ángeles, California, donde tenían las condiciones para editar Regeneración y tener múltiples contactos con la prensa ácrata de Estados Unidos y Europa. Basados en la mencionada publicación, se demuestra que concibieron su actividad como parte de la lucha revolucionaria anarquista que ya había empezado en México y buscaron la ayuda de los trabajadores del mundo, tanto para que arribaran a nuestro país como para expandir las expropiaciones en el orbe.

Los anarquistas del Partido Liberal Mexicano (PLM) han sido analizados sólo como parte del proceso revolucionario en México. Desde ese ángulo se han conformado una serie de afirmaciones sobre su actuación, mismas que se han convertido en un espacio común acerca de sus intenciones revolucionarias. Sin embargo, no se aborda su llamado insistente a la revolución mundial, lo que obliga a una interpretación más compleja, que no se apega a las limitadas explicaciones que surgieron en la posrevolución.

Palabras clave: revolución mundial, anarquistas, Partido Liberal Mexicano, Los Ángeles, frontera.

* Instituto de Investigaciones Históricas de la Universidad Autónoma de Baja California, Baja California, México. Correo electrónico: samaniego@uabc.edu.mx.

ORCID: https://orcid.org/0000-0003-4558-2342 


\section{Precursors of the world revolution}

\section{Abstract}

In Regeneración, the anarchists of the Mexican Liberal Party, from 1911 to 1918 , called on the American and European proletariat to carry out a world revolution that would end capitalism and all forms of authority. Their intention was to make them aware that they would expropriate all the means of production, so they stayed in Los Angeles, California, where they had the conditions to edit Regeneración and have multiple contacts with the acrat press in the United States and Europe. Based on the aforementioned publication, it is shown that they conceived their activity as part of the anarchist revolutionary struggle that had already begun in Mexico and sought the help of the workers of the world, both to arrive in our country and to expand expropriations in the world.

The anarchists of the Mexican Liberal Party (PLM) have been analyzed as part of the revolutionary process in Mexico. From that angle, a series of statements about his performance have been made, which have become a common space about his revolutionary intentions. However, their insistent call for world revolution is not addressed, forcing a more complex interpretation that does not adhere to the limited explanations that emerged in the postrevolution.

Key words: world revolution, anarchists, Partido Liberal Mexicano, Los Ángeles, border.

\section{Precursores da revolução mundial}

\section{RESUMO}

Em Regeneración, os anarquistas do Partido Liberal Mexicano, de 1911 a 1918, convocaram o proletariado americano e europeu a realizar uma revolução mundial que acabasse com o capitalismo e todas as formas de autoridade. A intenção era conscientizá-los de que expropriariam todos os meios de produção, por isso permaneceram em Los Angeles, Califórnia, onde tiveram condições de editar Regeneración e tiveram múltiplos contatos com a imprensa acratista dos Estados Unidos e da Europa. Com base na publicação citada, mostra-se que eles concebiam sua atividade como parte da luta revolucionária anarquista que já havia começado no México e buscavam a ajuda dos trabalhadores de todo o mundo, tanto para chegar em nosso país como para expandir as expropriações no mundo.

Os anarquistas do Partido Liberal Mexicano (PLM) foram analisados como parte do processo revolucionário no México. Desse ângulo, foram feitas uma série de afirmações sobre sua atuação, que se tornaram um espaço comum 
sobre suas intenções revolucionárias. No entanto, seu apelo insistente para a revolução mundial não é atendido, forçando uma interpretação mais complexa que não adere às explicações limitadas que surgiram na pós-revolução.

Palavras-chave: revolução mundial, anarquistas, Partido Liberal Mexicano, Los Angeles, fronteira.

\section{Precursores de la Revolución mundial}

Compañeros de todo el mundo: responded a nuestro llamamiento ahora que es tiempo de hacerlo, ahora que los compañeros mexicanos nos ponen el ejemplo de cómo hay que romper las cadenas de la iniquidad política, de la iniquidad económica, de la iniquidad social.

Regeneración, 29 de abril de 1911, p. 2.

Mira, cornudo de mis entretelas, los anarquistas no queremos la Anarquía solamente para México, sino para el mundo entero.

Ricardo Flores Magón, Regeneración, 11 de noviembre de 1916, p. 2.

Pero la semilla está sembrada. Vamos tranquilos al sacrificio, con la seguridad de que la semilla que con profusión hemos regado, tendrá que germinar.

Ricardo Flores Magón, Regeneración, 21 de abril de 1917, p. 1.

\section{INTRODUCCIÓN}

$\mathrm{C}^{1}$ propósito de este escrito es demostrar que las acciones de los anarquistas Cdel Partido Liberal Mexicano no estaban dirigidas únicamente a la revolución en México, sino a la pretensión de una revolución mundial. Las conclusiones a las que llegan numerosos autores es que los ácratas del PLM - con referencia especial a Ricardo Flores Magón — se quedó solo, alejado de las corrientes del movimiento armado y se limita la observación sobre las actividades de este grupo a dejarlos en una condición de "intelectuales", 
cuando ellos los repudiaban precisamente por no pasar a la acción. En este escrito argumentamos que permanecieron en Los Ángeles, California, Estados Unidos, porque estaban convencidos que era posible recibir ayuda de ácratas italianos y españoles — residentes en Estados Unidos-, así como del pueblo estadounidense y anarquistas de Europa. Permanecer en dicha ciudad permitió recibir las publicaciones ácratas de todo el orbe y enviar los ejemplares de Regeneración desde Estados Unidos a Sudamérica, Europa y Asia. Pero, sobre todo, el grupo tenía como objetivo formar conscientes que tomaran las armas y lograran lo que llegaría tarde o temprano, el sol de la anarquía en todo el mundo. Para ellos, la acción consistía en educar en el comunismo-anárquico a través de sus escritos y motivar a la expropiación de todos los bienes de producción.

En esta comunicación se citan referencias que corresponden de 1911 a 1918, cuando ellos abiertamente se declararon anarquistas, aunque en cartas personales o textos públicos ya habían manifestado su ideología. En los años mencionados se llamó en numerosas ocasiones a los ácratas del mundo y al pueblo estadounidense a seguir el ejemplo de los mexicanos, quienes, en su propaganda, ya estaban en una lucha universal, la revolución en México ya daba frutos porque los obreros y campesinos expropiaban todos los medios de producción, además de que se daba muerte a burgueses, funcionarios y sacerdotes.

De manera general apuntamos que los hermanos Flores Magón junto con Librado Rivera - para referirnos a los anarquistas - se fueron a Estados Unidos por la prohibición expresa de Porfirio Díaz de realizar publicaciones en su contra. Sin embargo, en dicho país era un delito ser anarquista. A pesar de ello, la presencia de ácratas fue significativa y los contactos de los anarquistas del PLM evidente. Ellos se ligaron directamente con los italianos de Paterson, Nueva Jersey, sobre todo con Ludovico Caminita y Luigi Galleani. En dicho lugar, un visitante frecuente era Enrico Malatesta. De igual forma se relacionaron directamente con los editores de Tierra y Libertad, de Barcelona, España y con ácratas, también españoles, de iTerra! en Cuba. Durante el período aquí señalado recibieron apoyo pecuniario y propagandístico de numerosas publicaciones en Estados Unidos o Argentina.

De igual forma estuvieron en contacto con Pedro Esteve, anarquista español que se trasladó a Paterson, donde editó La Questione Sociale y El Productor, misma que tuvo su origen en Barcelona a través del Grupo Cultural Regeneración. Destacamos este aspecto dado que la publicación de los anarquistas del PLM llevó el mismo nombre. Pero, sobre todo, demostramos que, en Regeneración, órgano de difusión de los anarquistas del PLM, se llamó a una revolución mundial durante ocho años. Las apologías sobre ellos, muchas de ellas aparentes y, en general, la historiografía de la revolución mexicana 
explica su actuación como una épica en contra de Díaz entre los años de 1892 y 1911, pero luego se simplifica la narrativa y se limita a la comparación con Francisco I. Madero. Posteriormente se destacan sus encarcelamientos y su muerte, dejando de lado que entre 1911 y 1918 realizaron una intensa campaña en favor de lograr el comunismo-anárquico. Incluso, se atribuye que en el Distrito Norte de la Baja California hubo un movimiento de seguidores de Ricardo Flores Magón, sin observar que los hombres que tomaron los poblados fronterizos no eran ácratas, no entendían las diferencias con Madero y que, muchos de ellos, se declararon maderistas, incluidos los indígenas cucapa, kumiai y kiliwa que participaron de lado insurgente.

La lucha anarquista ha quedado mencionada desde autores como Abad de Santillán (1925), Florencio Barrera (1955), Lowell L. Blaisdell (1963), Eduardo Blanquel (1963), Armando Bartra (1977), Lawrence Taylor (1991), Javier Torres Pares (1991), Colin Machlaclan (1991), o Claudio Lomnitz (2016), por mencionar algunos. Pero todos los analizan en la idea de que ellos encuadran en la revolución mexicana y son destacados en términos de fracaso, como un evento de orden nacional - incluso nacionalista - cuando ellos pretendían levantar en armas al proletariado del mundo para terminar con el capitalismo. En ello jugaba un papel importante el pueblo estadounidense y por ello su insistencia, desde Los Ángeles, California, que era indispensable seguir el ejemplo de los mexicanos que ya se encontraban en plena lucha contra el sistema de salarios, la propiedad privada, toda forma de gobierno y cualquier creencia religiosa.

Los análisis de la revolución mexicana les otorgan un espacio a los hermanos Flores Magón y en especial a Ricardo, por iniciar la lucha en contra del gobierno de Porfirio Díaz. Ello fue resultado de que, durante la posrevolución, los anarquistas del Partido Liberal Mexicano fueron transformados por el Estado posrevolucionario, y con el apoyo de varios ex militantes del PLM, entre ellos Enrique Flores Magón, se instituyó una forma de hacer referencia a este grupo como los precursores, los precursores intelectuales o el precursor, para referirse en exclusiva a Ricardo. ${ }^{1}$

Sin embargo, la crítica a sus acciones se volvió común, aun en autores que resaltan su participación para luego denostarlos, en especial a Ricardo. Así, Rafael Carrillo indicó que el anarquismo "esteriliza su acción y los coloca fuera el impetuoso torrente de la revolución". ${ }^{2}$ Barrera Fuentes lo considera obcecado

1 Kaplan, Samuel, Peleamos contra la injusticia. Enrique Flores Magón, el precursor de la revolución mexicana cuenta su historia, Ciudad de México, Libro Mex, 1960; Duffy Turner, Ethel, Ricardo Flores Magón y el Partido Liberal Mexicano, Morelia, Michoacán, Editorial Erandi, 1960; Anaya, Pedro María, Precursores de la Revolución Mexicana, Ciudad de México, Secretaría de Educación Pública, 1955; Gill, Mario, “Turner, Flores Magón y los filibusteros", Historia Mexicana, vol. 4, núm. 5, 1956, pp. 642-663.

2 Carrillo, Rafael, Ricardo Flores Magón. Esbozo biográfico, (s.e. 1945), p. 60. 
y lo descalifica en relación con Francisco I. Madero. ${ }^{3}$ González Monroy, quien fuera miembro del PLM lo adjetivó como dictador, imprevisor e imprudente. ${ }^{4}$ Eduardo Blanquel lo consideró irracional, carente de ideas y desconocedor del anarquismo. ${ }^{5}$ Lowell L. Blaisdell señaló su falta de talento para administrar, fanático, suspicaz, despiadado con sus enemigos y amargado. ${ }^{6}$ Armando Bartra ubicó al grupo en ".. aislamiento con respecto al estado real de las masas determinó que, a la larga, las consignas y reivindicaciones tuvieran que ser necesariamente subjetivas y ajenas a los deseos y posibilidades reales".? Claudio Lomnitz señaló que Ricardo era intransigente, malagradecido, utopista, inflexible, incontinente, amargado, resentido, agresivo, violento y sañudo. ${ }^{8}$

A pesar de estas afirmaciones, el "reconocimiento" de precursores de la revolución mexicana prevaleció en numerosos discursos y obras que alaban el Programa del Partido Liberal Mexicano de julio de 1906, elaborado principalmente por Juan Sarabia, quien no fue anarquista. En el año 2000, el nombre de Ricardo Flores Magón fue colocado con letras de oro en la Cámara de Diputados, bajo la idea de que éste, como precursor elaboró el programa ya mencionado, base de la Constitución de 1917. Así, en el decreto correspondiente del 15 de marzo de 1999, se plasmó que para Ricardo "la soberanía era sinónimo de una patria libre, no sujeta a tutela extranjera alguna $\mathrm{y}$ en donde exista un derecho que permita a los ciudadanos dictar sus propias leyes, elegir a sus gobernantes y decidir el rumbo del país". ${ }^{9}$

Así el anarquista que publicó que el principal autor del programa fue Juan Sarabia, el que estaba en contra de la ley, los gobiernos, la patria y los patrioteros, el Estado y toda forma de creencia religiosa, fue colocado con base en los argumentos de numerosos diputados que el aludido hubiera repudiado

3 Barrera Fuentes, Florencio, Historia de la Revolución mexicana. Etapa precursora, Ciudad de México, Instituto Nacional de Estudios Históricos de la Revolución Mexicana, p. 23.

$4 \quad$ Monroy, Jesús González, Ricardo Flores Magón y su actitud en Baja California, Ciudad de México, Editorial Academia Literaria, 1962, pp. 150-152.

5 Blanquel, Eduardo, Ricardo Flores Magón y la Revolución mexicana, y otros ensayos, Ciudad de México, prólogo, selección y edición de Josefina Mac Gregor, El Colegio de México, 2008, p. 107.

6 Blaisdell, Lowell L., The Desert Revolution. Baja California, 1911, The University of Wisconsin Press, 1962, p. 56.

7 Bartra, Armando, "Introducción”, Regeneración. 1900-1918. La corriente más radical de la revolución mexicana de 1910 a través de su periódico de combate, Ciudad de México, Editorial Era, 5a. edición, 1985, p. 33.

8 Lomnitz, Claudio, El regreso del camarada Ricardo Flores Magón, Ciudad de México, Ediciones Era, 2016, pp. 289, 330, 357, 374, 394, 420, 430, 522, 526, 581.

9 Cámara de Diputados del H. Congreso de la Unión, LIX legislatura, Colección Muro de Honor, 133. http://www.diputados.gob.mx/LeyesBiblio/muro/pdf/floresm.pdf [consultado el 10 de julio de 2020]. 
fervientemente por representar todo aquello a lo que dedicó su vida: destruir la autoridad. Fue "reconocido" en numerosas ocasiones, tanto por organizaciones obreras o campesinas, por dar el programa que propuso las reformas sociales en contra de las que estaba: salarios, pensiones, huelgas, reparto agrario. En cambio, el planteamiento de expropiar todos los medios de producción quedó de lado y en los escritos que alaban su actuación, aparece siempre la crítica.

\section{LOS PRECURSORES DE UNA REVOLUCIÓN EN TODO EL MUNDO}

En 1916, en la primera página de Regeneración, apareció constantemente un escrito que apuntaba que la revolución en México era un movimiento del pobre contra el rico. En el segundo punto indicaron que su publicación "se ha esforzado y se esfuerzan por encauzar el movimiento por el sendero del comunismo anárquico". Posteriormente, indicaron que los trabajadores que "piensan y sienten ansias de redención están con nosotros". En contra sólo estaban los impotentes, unos cuantos despechados envidiosos que "sacrifican los principios anarquistas a la satisfacción de rencores irracionales y bajos". ${ }^{10}$

Desde 1910, las referencias a un llamado mundial se evidenciaron en las páginas de Regeneración. En noviembre, Ricardo Flores Magón argumentó cuales eran las aportaciones de los mexicanos al gran movimiento universal en contra de los potentados. Las diferentes organizaciones estaban ya en marcha y México, debido a las condiciones de pobreza, "será la primera nación del mundo que dé un paso franco por el sendero los pueblos todos de la tierra, aspiración poderosa que agita a la humanidad entera sedienta de libertad, ansiosa de justicia". ${ }^{11}$ Durante los acontecimientos armados en el Distrito Norte de la Baja California, movimiento que inicialmente estuvo bajo la bandera del PLM y que luego de unas semanas, surgieron otros grupos con diferentes intenciones, las referencias al proletariado mundial se volvieron más frecuentes. ${ }^{12}$

El 8 de abril, publicaron un manifiesto a los trabajadores del mundo. Explicaron que el gobierno de Taft movilizó 20000 hombres a la frontera con México y llamaron a la agitación de los trabajadores en contra de los gobiernos que veían con temor el avance de los revolucionarios mexicanos. Indicaron que debía de comprenderse "el peligro en que nos encontramos enfrente de todos los gobiernos del mundo, que ven en el movimiento mexicano la aparición

10 Sin autor, “AAtención!” Regeneración, Los Ángeles, 1 de enero de 1916, p. 1. La columna apareció en la primera página durante tres meses.

11 Flores Magón, Ricardo, “En pos de la Libertad”, Regeneración, Los Ángeles, 5 de noviembre de 1910 , p. 2.

12 Samaniego, Marco Antonio, Nacionalismo y revolución. Los acontecimientos de 1911 en Baja California, Tijuana, Centro Cultural Tijuana-Universidad Autónoma de Baja California, 2008. 
de la revolución social, la única que temen los poderosos de la tierra". ${ }^{13}$ De igual forma, al narrar cómo la prensa ácrata de Estados Unidos y Europa se ocupaba de la revolución en México, indicaron que pronto "este movimiento se extenderá por todo el mundo" y el PLM tendría el apoyo solitario de los desheredados de la tierra. ${ }^{14}$

Poco después, ante la muerte de un estadounidense miembro de la Industrial Workers of the World, Stanley Williams, se indicó que en los campos de México se generaba la lucha "que mañana será combatida en los Estados Unidos y pasado, en todos los pueblos de Europa y el resto del mundo hasta conseguir la completa eliminación del capitalista, el déspota y el fraile". ${ }^{15}$ Ricardo Flores Magón publicó que los periódicos obreros de Estados Unidos y Europa era parte de una agitación formidable, "cómo debe ser, pues la clase trabajadora de todo el mundo no debe dejarnos solos en la lucha contra el enemigo común: el capital". ${ }^{16}$ La conocida anarquista de origen ruso, Emma Goldman, publicó que la revolución en México era la lucha por la causa de la libertad de toda la humanidad, era una batalla en el mundo para la emancipación. Goldman indicó que no era una cuestión de ismos, sino de los trabajadores en Estados Unidos y en todo el mundo. ${ }^{17}$

El 8 de mayo de 1911, con la ocupación del poblado de Tijuana y ante la inminente llegada de anarquistas de varios lugares de Estados Unidos como resultado de sus relaciones con ácratas de Barre, Vermont y Paterson, Nueva Jersey, y sus publicaciones Cronaca Sovversiva y L'Era Nuova, Ricardo Flores Magón llamó a los anarquistas italianos y españoles a poblar el Distrito Norte de la Baja California. Indicó que existían abundantes tierras y agua para todos los que llegaran; no se trataba de formar una república, "no nos conformamos con tan poca cosa", la Baja California "será la base principal de nuestras operaciones para llevar la Revolución Social a todo México y a todo el mundo". ${ }^{18}$ Debido al apoyo pecuniario de Tierra y Libertad y de otras publicaciones anarquistas

13 Flores Magón, Ricardo, Antonio de P. Araujo, Librado Rivera, Anselmo L. Figueroa, Enrique Flores Magón, "Manifiesto a los trabajadores de todo el mundo", Regeneración, Los Ángeles, 8 de abril de 1911, p. 1.

14 Flores Magón, Ricardo, "Movimiento de solidaridad", Regeneración, Los Ángeles, 8 de abril de 1911, p. 1.

15 De Pío Araujo, Antonio, "William Stanley”, Regeneración, Los Ángeles, 15 de abril de 1911, p. 1. El nombre era Stanley Williams, por lo que todo indica que Araujo apenas conocía al personaje. Cabe señalar que el 1 de marzo, Ricardo Flores Magón había escrito que no se permitiera el ingreso de Williams.

16 Flores Magón, Ricardo, "Movimiento de solidaridad", Regeneración, Los Ángeles, 22 de abril de 1911, p. 2.

17 Goldman, Emma, "Emma Goldman in hearty simpathy”, Regeneración, Los Ángeles, 22 de abril de 1911, p. 4.

18 Flores Magón, Ricardo, "Notas al vuelo", Regeneración, Los Ángeles, 20 de mayo de 1911, p. 2. 
de Europa y Estados Unidos, se demostraba que la solidaridad en pocas semanas "se habrá hecho universal". ${ }^{19}$ En Tierra y Libertad los ácratas del PLM publicaban que la revolución en México era anarquista y llamaban a los españoles a sumarse a la contienda. Así, en el "manifiesto a los trabajadores del mundo", se indicaba que la lucha en México era el primer "acto de la tragedia universal que bien pronto tendrá por escenario toda — sic- el planeta". En la nueva era, que sería la patria universal de los libres y de los hermanos, la revolución social en México se desarrollaba a la vista y preguntaba "¿Y qué esperáis para obrar? ¿Aguardáis a que este generoso sea aplastado para llenar el espacio con vuestras protestas que serán impotentes para volver a la vida a vuestros mejores hermanos y para extirpar de los pechos el desaliento que provocaría el fracaso, fracaso que vosotros mismos habíais preparado con vuestra indiferencia?". Por ello era indispensable obrar de inmediato y cumplir con el deber. ${ }^{20}$ Anselmo Lorenzo, haciendo eco de Regeneración, publicó que en México se luchaba sin distinción de raza, nacionalidad ni idioma, tomando la tierra en común y anulando el sistema de salarios. Era la primera revolución con programa concreto, en el que se tomaba posesión efectiva de la tierra y de la maquinaria mediante la expropiación a los "propietarios usurpadores". ${ }^{21}$

En junio de 1911 el contingente armado que no tuvo como lucha central el anarquismo, pero que en buena parte de la historiografía ha sido simplificada como una supuesta "revuelta magonista" o de liberales, sin observar que sí hubo propuestas de socialistas para formar una república o de auténticos anexionistas, anarquistas como Ludovico Caminita, negaron que ese movimiento hubiera sido parte de la lucha del PLM, afirmación que fue sustentada después por Antonio de Pío Araujo. ${ }^{22}$ Para ellos, el gran movimiento social continuaba, no para llevar a alguien al poder, sino para no llevar a nadie. Por ello, en julio de 1911 Antonio de Pío Araujo publicó que, a pesar de lo sucedido en Baja California, esperaban "que el proletariado mundial venga a nosotros con elementos necesarios para sostener lo conquistado". Para ellos, México estaba ya en camino al comunismo.

19 Flores Magón, Ricardo, "Movimiento de solidaridad", Regeneración, Los Ángeles, 22 de mayo de 1911, p. 3.

20 Flores Magón Ricardo , Antonio de Pío Araujo, Librado Rivera, Anselmo Figueroa, Enrique Flores Magón, "Manifiesto a los trabajadores de todo el mundo", Tierra y Libertad, Barcelona, 3 de mayo de 1911, p. 2.

21 Lorenzo, Anselmo, "La revolución en Méjico" Tierra y Libertad, Barcelona, 28 de junio de 1911, p. 1. Cabe señalar que, para ese momento, la lucha armada en el Distrito Norte de la Baja California ya había terminado y nunca se expropió tierra ni maquinaria. Lo que realmente ocuparon algunos de los participantes fueron las incipientes cantinas de Mexicali y Tijuana.

22 Samaniego, "El poblado", pp. 1149-1150. 


\section{Un año de triunfos y expropiaciones en Regeneración (Los Ángeles), julio 1911-junio 1912}

El llamado a sumarse al movimiento expropiador se mantuvo con intensidad. La alusión a que sólo con la expropiación de la tierra y la maquinaria se lograría el triunfo del proletariado se demostraba en las páginas de Regeneración. En la narración de la revolución que realizaba Enrique Flores Magón, el pueblo empezó a expropiar y a imponer el comunismo. Nadie quería la democracia que pretendía establecer Madero. "Muera la boleta electoral", fue el grito de los indios de Oaxaca para negar la lucha democrática. ${ }^{23}$ “Paso al proletariado! La onda expropiadora se extiende, adelanta y alcanza ya a la capital de la república", indicó en octubre de 1911: "La angustia de Madero no tiene límites. La revolución mexicana ha tomado tal fuerza en estos últimos Días que Madero, loco de terror, se echa en brazos de Wall Street y demanda la intervención americana", señalaron en febrero de 1912. Enrique, en "Viva la violencia" luego de narrar las numerosas expropiaciones que se realizaban, indicó que los valerosos luchadores continuaban su obra en contra de los explotadores. La acción directa se ejercía en una combinación muy especial, ya que iban

arrasando campos a la vez que expropiando, acosando a los burgueses por cuantos medios se puede, abriendo los graneros y almacenes de los ricos para que los pobres satisfagan sus necesidades, quemando casas de burgueses y archivos públicos a montones, llevando, en fin, el terror al ánimo de los ricos y templando con su ejemplo el carácter de los pusilánimes, haciéndoles perder el respeto al inicuo derecho de propiedad privada. ${ }^{24}$

Bajo esta lógica, los titulares y las alusiones a numerosas expropiaciones, a la violencia como única forma de acabar con la burguesía, funcionarios y clero, se narró en numerosas ocasiones. Esta afirmación es aplicable hasta 1918; bien puede afirmarse que con palabras semejantes se publicó en casi todos los números de Regeneración.

Aristide Pratelle, cercano colaborador francés, señaló que en Regeneración se publicaban las verdaderas explicaciones sobre la revolución y era fundamental, dado que el "porvenir del movimiento revolucionario mundial depende de este hecho". A los trabajadores de los dos continentes Pratelle les

23 Flores Magón, Enrique, “¡Muera la boleta electoral!”, Regeneración, Los Ángeles, 7 de octubre de 1911, p. 1.

24 Flores Magón, Enrique, “¡Viva la violencia!”, Regeneración, Los Ángeles, 23 de marzo de 1912, p. 1-2. 
indicó que Regeneración mostraba el camino que deberían seguir si querían romper las cadenas de la esclavitud. ${ }^{25}$

El avance de los expropiadores, apuntó Ricardo Flores Magón, llamaba la atención de todos los gobernantes del mundo. Los revolucionarios obligaban al gobierno estadounidense a intervenir, pero eso abriría los ojos al pueblo americano, quien no estaba dispuesto a luchar por los ricos. Pero la burguesía europea presionaría para la intervención y se mandarían tropas a México, "pero como el pueblo americano, protestarían a su vez los pueblos europeos y la Revolución Social se hará en todo el mundo". El grito de Tierra y Libertad se escucharía en España, Italia, Inglaterra, Alemania, "y en todas partes, y comenzará para la humanidad una Nueva Era". ${ }^{26}$

\section{Antonio de Pio Araujo: el final inevitable. Julio de 1912- enero de 1914}

Ricardo y Enrique Flores Magón, Anselmo L. Figueroa y Librado Rivera, fueron encarcelados por violación de las leyes de neutralidad de julio de 1912 a enero de 1914. En ese período, Antonio de Pío Araujo tomó un papel central por la cantidad de escritos publicados. Rafael Romero Palacios y Juan Francisco Moncaleano, Francisca J. Mendoza, también tuvieron un papel protagónico, pero en poco tiempo se confrontaron con los anarquistas encarcelados. Blas Lara, Teodoro Gaytán y Antonio de Pío Araujo mantuvieron la publicación en el mismo sentido que los encarcelados.

Al narrar los sucesos en México se mantuvo la línea de considerar que era una revolución anarquista triunfante. "¡Paso a la revolución social! ¡Abajo el gobierno! ¡Muera el capital!”, escribió Francisca J. Mendoza para señalar los numerosos grupos revolucionarios que, en las páginas de Regeneración, expropiaban, quitaban autoridades y eliminaban sacerdotes. ${ }^{27}$ "El comunismo en México es inevitable. La revolución lo exige"; 28 "El sol de la libertad ilumina los campos revolucionarios"; 29 "La bandera roja ondea en los principales edificios de Córdoba, Veracruz"; 30 "El carrancismo en aprietos. Pero la

25 Pratelle, Aristide, "Solidaridad mundial", Regeneración, Los Ángeles, 23 de marzo de 1912, p. 3. Aristide Pratelle fue uno de los difusores de los anarquistas mexicanos en Europa desde 1907.

26 Flores Magón, Ricardo, "Más sobre la intervención”, Regeneración, Los Ángeles, 27 de abril de 1912, p. 1.

27 Mendoza, Francisca J., “¡Paso a la revolución social! ¡Abajo el gobierno! ¡Muera el capital!”, Regeneración, Los Ángeles, 17 de agosto de 1912, p. 2.

28 Carta firmada "De tierra y libertad”, Regeneración, Los Ángeles, 30 de noviembre de 1912, p. 1.

29 Juan Francisco Moncaleano, "El sol de la libertad ilumina los campos revolucionarios", Regeneración, Los Ángeles, 25 de enero de 1913, p. 1.

30 De Pío Araujo, Antonio, "La bandera roja ondea en los principales edificios de Córdoba, Veracruz", Regeneración, Los Ángeles, 10 de mayo de 1913, p. 1. 
verdadera revolución marcha". ${ }^{31}$ En las notas, tomadas de otros periódicos, se indicaba que los libertarios comunistas iban expropiando, entregando las tierras en colectivo, sin cometer el error de dar parcelas individuales.

La revolución social en México, "muestra grandes actos justicieros de la plebe, que mantiene vivos los ánimos del proletariado mundial en el curso que lleva". ${ }^{32}$ Juan Francisco Moncaleano, en agosto de 1912, al defender a Ricardo, apuntó que éste "solo tiene palpitaciones en pro de la redención mundial". Buscaba "formar de todas las naciones del mundo una patria universal donde todos los miembros de la humana especie unidos por el respeto mutuo a la libertad y la igualdad y cobijados por la bandera del trabajo, sin leyes ni tiranos...". Ricardo, indicó Moncaleano, lo que quería era que la burguesía trabajara e implantar en el mundo "la verdadera igualdad sin superiores ni inferiores, sin esclavos ni esclavizadores, el mundo del amor y el trabajo". ${ }^{33}$ Antonio Loredo, publicó en Cultura Proletaria (Uruguay) que en México se jugaba el porvenir del mundo. Todos los anarquistas debían unirse en "un movimiento universal de todos los pueblos. Lo necesario en estos momentos es aprovechar los acontecimientos y provocarlos si se quiere llegar cuanto antes a la meta de nuestras aspiraciones". De Pío Araujo citó la nota, con el señalamiento de llevar adelante el triunfo de Tierra y Libertad. ${ }^{34}$

De Pío Araujo en los siguientes meses afirmó que el pueblo estadounidense, cansado de tanto abuso, se uniría a la lucha. Si los proletarios americanos apoyaban físicamente a los revolucionarios mexicanos y se sumaban los apoyos pecuniarios y morales de solidaridad mundial, "el capitalismo yankee puede ser barrido en la lucha de clases internacional que se avecina y Norte América quedar emancipado del sistema capitalista". ${ }^{35} \mathrm{Al}$ pasar de los meses, aparece una de las preguntas que se repite en los siguientes años, ¿por qué no acudían los proletarios, si los mexicanos ya ponían el ejemplo con las expropiaciones para que el mundo los imitara? ${ }^{36}$ Sin embargo, las notas sobre los avances de los expropiadores seguían dado que, para ellos, era una revolución social-

31 Anarquista, "El carrancismo en aprietos. Pero la verdadera revolución marcha", Regeneración, Los Ángeles, 4 de octubre de 1913, p. 2.

32 De Pío Araujo, Antonio, "La revolución social en México", Regeneración, Los Ángeles, 27 de julio de 1912, p. 1.

33 Moncaleano, Juan Francisco, "Ricardo Flores Magón en la prisión", Regeneración, Los Ángeles, 31 de agosto de 1912, p. 1. Poco tiempo después Moncaleano se confrontó a los anarquistas del PLM, en particular con Ricardo.

34 Citado por Antonio de Pío Araujo, "Revisando la prensa", Regeneración, Los Ángeles, 31 de agosto de 1912, p. 3.

35 De Pío Araujo, Antonio, "Frente a la invasión”, Regeneración, Los Ángeles, 26 de octubre de 1912, p. 1.

36 López, Juan José, "La revolución mexicana", Regeneración, Los Ángeles, 14 de diciembre de 1912 , p. 1. 
económica con el triunfo asegurado porque el pueblo mexicano era comunista por tradición. En la lucha desigual, los comunistas mexicanos confrontados con el capitalismo yankee

esperamos que los trabajadores del mundo vengan a nuestra ayuda y con sus grandiosas protestas en las grandes metrópolis de Europa y las Américas contra los actos de los Estados Unidos y sus constantes contribuciones financieras y morales a los revolucionarios, impidan que el primer movimiento del proletariado consciente sea ahogado en sangre y la marina por el estado capitalista. ${ }^{37}$

Araujo se mostraba feliz por el bello espectáculo que ofrecía México al mundo. Se eliminaba a la burguesía por medio de la violencia y se presentaba "una situación sin paralelo en la historia de los pueblos". El triunfo, "será nuestro si la solidaridad mundial es un hecho". ${ }^{38}$ Así, pues, con la ayuda del proletariado mundial se lograría terminar con el capitalismo. La obra ya estaba empezada y debía terminarse, "en estos preciosos momentos el obrero consciente mundial, tiene la vista fija en el grandioso escenario en que vosotros presentáis tan hermosos dramas, cortando cabezas de autoridades, fusilando ricos y declarando la propiedad común". ${ }^{39}$ En agosto de 1913, de Pío Araujo insistió en que "si hubiera una acción enérgica y solidaria de los trabajadores conscientes de las naciones interventoras, no digamos que el comunismo fuera ahogado en México, sino entonces, la Revolución Social se extenderá en los países interventores y el capitalismo enfrentaría una situación que podría arrojarlo para siempre de la faz de la tierra". ${ }^{40}$

\section{4-1918. Desde Los Ángeles, o desde la cárcel, pero la revolución será mundial}

En enero de 1914 salieron de la cárcel Enrique y Ricardo Flores Magón, Anselmo L. Figueroa y Librado Rivera. Al poco tiempo Antonio de Pío Araujo abandonó el grupo para unirse a las fuerzas de Zapata en el estado de Morelos, aunque no parece haber tenido impacto en el caudillo suriano. En los siguientes años, Ricardo, Enrique y Librado ingresaron varias veces a la cárcel, mientras que Regeneración era publicado por Lucía Norman y Estela Arteaga, hijastras de Ricardo y Enrique, respectivamente. Así mismo, hubo períodos largos en que la publicación dejó de aparecer.

37 De Pío Araujo, Antonio, "La intervención americana y la voracidad yankee”, Regeneración, Los Ángeles, 1 de febrero de 1913, p. 1.

38 De Pío Araujo, Antonio, “La situación”, Regeneración, Los Ángeles, 8 de febrero de 1913, p. 1.

39 Anarquista, “Grande población saqueada", Regeneración, Los Ángeles, 24 de mayo de 1913, p. 2.

40 De Pío Araujo, Antonio, "La revolución en el sur de la República”, Regeneración, Los Ángeles, 2 de agosto de 1913, p. 1. 
Igual que en los años anteriores, en las páginas de Regeneración el movimiento expropiador avanzaba, sobre todo con el inicio de la Gran Guerra, momento considerado como excepcional para la revolución mundial. Así, en "Rebeldías proletarias" daban cuenta de los avances expropiadores; ${ }^{41}$ en "sigue la pelotera", Enrique indicaba que con la gran guerra se lograría lo que ellos no pudieron hacer, "que el proletariado americano se decida al fin a seguir el ejemplo mexicano y se levante en armas contra sus opresores y explotadores al sentirse empujado a una guerra desastrosa y sin provecho para los pobres". ${ }^{42}$ Regeneración sería enviado a China e Indostán, Japón, Filipinas y Corea, para que conocieran la revolución social en México, donde serviría "mucho a los revolucionarios de aquellos viejísimos pueblos para los fines que todos nos proponemos: la libertad económica mundial". ${ }^{43}$ En abril, un libertario señaló que el proletariado debería hacer suya la revolución mexicana, y "el esfuerzo del proletariado mundial debe ser unánime y extremo. Los revolucionarios deben organizarse y formar una avalancha de hombres bien pertrechados y hacer irrupción en México". ${ }^{44} \mathrm{Si}$ en México se pierde, se pierde en el mundo, apuntó Ricardo, dado que se desarrollaba "el primer acto de la tragedia que ha de terminar en todo el mundo con la muerte del privilegio por la plebe dignificada y redimida". ${ }^{45}$ La invasión por tropas estadounidenses al puerto de Veracruz en abril de 1914 provocaría la unión del proletariado americano, que "sufre lo mismo que el proletariado mexicano". ${ }^{46}$ Por ello no se debía temer la invasión americana. ${ }^{47}$ De igual forma señaló que la sangre derramada en las campañas mexicanas era "para bien de la humanidad, para que esta se emancipe; pero al fin de todo, batallando contra obstáculos y dificultades, la verdad tiene que abrirse paso y esplendente y triunfadora iluminará al mundo proletario en su camino hacia la sociedad futura". ${ }^{48}$

$41 \quad$ Flores Magón, Ricardo, "Rebeldías proletarias", Regeneración, Los Ángeles, 7 de marzo de 1914, p. 2.

42 Flores Magón, Enrique, “iSigue la pelotera!”, Regeneración, Los Ángeles, 30 de mayo de 1914, p. 2.

43 Sin autor, "Regeneración en el oriente", Regeneración, Los Ángeles, 21 de marzo de 1914, p. 3 .

44 Un libertario, "La leva revolucionaria", Regeneración, Los Ángeles, 25 de abril de 1914, p. 2.

45 Flores Magón, Ricardo, "La intervención americana", Regeneración, Los Ángeles, 9 de mayo de 1914, p. 2.

46 Flores Magón, Ricardo, "Cantos de sirena de Woodrow Wilson”, Regeneración, Los Ángeles, 30 de mayo de 1914, p. 1.

47 Flores Magón, Enrique, "Revisando la prensa", Regeneración, Los Ángeles, 30 de mayo de 1914, p. 2.

48 Flores Magón, Enrique, “Obra educadora”, Regeneración, Los Ángeles, 27 de junio de 1914, p. 2. 
La guerra mundial era, para los anarquistas del PLM, un momento de regocijo porque sólo ante la enorme mortandad los pueblos se darían cuenta del error de la patria, que "no es nuestra madre: jes nuestro verdugo!". Por ello, la catástrofe mundial "es un mal necesario". Los pueblos fueron envilecidos por la sociedad burguesa y habían olvidado sus derechos. La revolución mexicana "extenderá sus flamas bienhechoras por toda la tierra, y en lugar de cabezas de proletarios, rodarán por el suelo cabezas de los ricos, de los gobernantes y de los sacerdotes y un sólo grito subirá al espacio escapado del pecho de millones y millones de seres humanos: ¡Viva tierra y libertad!”. ${ }^{49} \mathrm{La}$ causa de la emancipación de los trabajadores, apuntó Ricardo, "no reconoce fronteras". ${ }^{50}$

Estela Arteaga, hijastra de Enrique, durante una de las estancias en la cárcel del mencionado, señaló que los movimientos en Europa superarían la "embriaguez patriótica" y el ejemplo de los mexicanos, al seguir las expropiaciones "puede cundir en los países europeos e incitar a las masas de aquellos países, desengañados de que ahora están degollando en beneficio de los amos, pero principalmente empujados por el hambre, a luchar también ellos por destruir el presente sistema capitalista e implantar una sociedad nueva de iguales y libres" ${ }^{51}$ Con el inicio de la revolución rusa en 1917, Regeneración clamó la llegada de la revolución mundial. Rusia había iniciado la gran transformación. En Alemania, Inglaterra, Austria-Hungría, Italia, Grecia y Estados Unidos, todos los pueblos llegarían a convencerse de que "mientras no se conquiste para cada ser humano el derecho a la vida la injusticia y el hambre serán los frutos naturales de su ceguera". Nadie podría permanecer indiferente ante la catástrofe, "porque todos nos veremos envueltos en las llamas bienhechoras". 52

\section{El PAPEL De REgeneración: CREAR CONSCIENTES DESDE LoS Ángeles, California}

En mayo de 1911, Ricardo Flores Magón le escribió al anarquista español Pedro Esteve para indicarle que los hombres que ocuparon Tijuana no comprendían los ideales de los miembros de la junta. La división especial, es decir, los anarquistas italianos que habían llegado en esos días de varias partes

49 Flores Magón, Ricardo, "La patria burguesa y la patria universal", Regeneración, Los Ángeles, 9 de octubre de 1915, p. 2.

50 Flores Magón, Ricardo, "Excitativa a los trabajadores del mundo", Regeneración, Los Ángeles, 8 de enero de 1916, p. 3.

51 Arteaga, Estela, "El hambre”, Regeneración, Los Ángeles, 11 de marzo de 1916, p. 2.

52 Flores Magón, Ricardo, "El contagio", Regeneración, Los Ángeles, 24 de marzo de 1917, p. 1. 
de Estados Unidos abrirían "los ojos a los tímidos y hará que los escuden en su obra purificadora". ${ }^{53}$ Por ello, "necesitamos en los lugares conquistados por el Partido Liberal Mexicano compañeros que eduquen a los inconscientes". ${ }^{54}$

Este escrito, lejos de demostrar el éxito de los hombres que ocuparon poblaciones del Distrito Norte de la Baja California a principios de 1911, demuestra la diversidad de objetivos y que los hombres en armas no conocieron de la lucha ácrata de los miembros anarquistas de la junta. ${ }^{55}$ La versión equívoca es decir que dicho grupo era "magonista", cuando la diversidad de objetivos fue evidente. En esos días muchos de los miembros del contingente se declararon maderistas. La paz, de hecho, se firmó bajo los Tratados de Ciudad Juárez, es decir, como si los acontecimientos en Baja California hubieran sido parte de la lucha del hacendado coahuilense.

Los Ángeles fue la ciudad que desde 1907 se convirtió en su centro de actividades ¿Por qué se quedaron en dicho lugar? ¿Por qué no se trasladaron al supuesto lugar controlado por ellos, el Distrito Norte de la Baja California? La respuesta es sencilla: en Los Ángeles tenían los medios que les permitían realizar la labor que ellos consideraban fundamental para el advenimiento del anarquismo: crear conscientes. Es decir, convencer a los individuos que de manera libre y autónoma comprendieran la filosofía anarquista e iniciaran con las expropiaciones, sin seguir líderes ni jefes, sino tomando posesión de la tierra y de todos los medios de producción: maquinaria, equipos, herramientas, fábricas, para luego repartir todo en común, sin propiedad privada, sin autoridades ni gobierno alguno, sin ningún tipo de creencia religiosa.

Desde Los Ángeles lograron estar en contacto con los anarquistas de Paterson, Nueva Jersey, como Luigi Galleani, Frances Widmar, Ludovico Caminita o los hermanos Cravello, estos últimos se sumaron a la junta del PLM. De igual forma, lograron iniciar y mantener la relación con Tierra y Libertad, de Barcelona, España, publicación que además de retomar textos de la junta, aportaron recursos económicos. Desde ahí, enviaron y recibieron publicaciones y entablaron relación con publicaciones anarquistas como Mother Earth, que circulaba en Estados Unidos, La Huelga General y Tierra y Libertad, de Barcelona, España, The Emancipator, de Home, Washington, L'Era Nuova y La Questione Sociale, de Paterson, Nueva Jersey, Cronaca Sovversiva, de Barre, Vermont, Les Temps Nouveaux y Le Libertaire, de París, Francia. De igual forma, mantuvieron relación con Pedro Esteve y Jaime

53 Samaniego, "El poblado", pp. 1120-1132.

54 Ricardo Flores Magón a Pedro Esteve, 22 de mayo de 1911, en archivo electrónico Ricardo Flores Magón, consultado el 10 de junio de 2020 en http://archivomagon.net/obrascompletas/correspondencia-1899-1922/c-1911/cor325/.

55 Samaniego, "Las estrategias", pp. 125-140. 
Vidal, que editaban Cultura Proletaria y Cultura Obrera. ${ }^{56}$ En el caso de haberse trasladado a Tijuana o Mexicali no habrían tenido esa posibilidad. En ninguna de estas poblaciones había telégrafo ni mucho menos imprenta. La comunicación telefónica era posible al cruzar a Estados Unidos, ya fuera en Campo, San Isidro o Calexico, pero no desde las poblaciones mexicanas.

Dicho de manera sencilla, su pretensión de unir a los trabajadores del mundo era posible intentarla desde Los Ángeles, California, no desde las incipientes poblaciones mexicanas de la frontera. Sin embargo, la razón más importante, porque no pretendían una revolución que se limitara a México, sino una de carácter universal que vinculara a todos los desposeídos. Era la lucha universal por una humanidad sin privilegios. Por ello, el llamado a sumarse a lo que ellos llamaron el movimiento más hermoso en la historia de la humanidad: la revolución social en México. Así, para crear conscientes, Los Ángeles, California, era uno de los espacios que les permitía realizarlo, a pesar de que por ser anarquistas existía la amenaza constante de nuevos encarcelamientos y persecuciones, como efectivamente sucedió. Despertar al pueblo estadounidense era un factor considerado clave por Enrique, quien como vimos, ansiaba, "que el proletariado americano se decida al fin a seguir el ejemplo del mexicano, y se levante en armas contra sus opresores y explotadores al sentirse empujado a una guerra desastrosa y sin provecho para los pobres". Así, no se perdieron del torrente de la revolución mexicana, no eran los precursores que abandonaron la lucha para vivir encarcelados eternamente por su perseguidores, sino que, en el contexto estadounidense donde anarquistas como Emma Goldman y Luigi Galleani actuaban, ellos, aprovechando el movimiento revolucionario mexicano, como medio, no como fin, insistieron durante ocho años que la revolución en México ya era expropiadora de la tierra y de los medios de producción y que todos los proletarios del mundo debían aprovechar el feliz momento. ${ }^{57}$

El mundo planteado por Ricardo en enero de 1911 necesitaba conscientes que trabajaran la tierra en común, según las necesidades de cada cual, "no cometáis, compañeros, la locura de cada quien cultivar un pedazo. Os matareis en el trabajo exactamente como os matáis hoy. Uníos y trabajad la tierra en común, pues todos unidos la haréis producir tanto que estaréis en aptitud de alimentar al mundo entero". Así, únicamente se trabajarían dos o tres horas

56 Cultura Proletaria se publicó en 1910 y 1911 en Nueva York; Cultura Obrera de 1911 a 1925. En los dos casos se reproducían textos de Regeneración en los que se informaba del avance del anarquismo en México.

57 La cronología de Jacinto Barrera y Armando Bartra, es un ejemplo de terminar la actividad revolucionaria en 1911 para luego mencionar los encarcelamientos posteriores. Véase, Armando Bartra, Jacinto Barrera, La revolución magonista (cronología narrativa), 2018, pp. $1-384$ 
diarias, en posesión común de la tierra y la maquinaria. Con ello, todos gozarían de todo, haciendo a un lado la codicia, la prostitución, la falsedad que otorga el uso del poder. ${ }^{58}$

Por ello, era necesario que no hubiera líderes o jefes que dieran órdenes o solicitaran esperar al triunfo del movimiento para repartir la tierra. Por el contrario, a todo jefe que no repartiera la tierra de inmediato había que matarlo. La masa eran esos niños retrasados que esperan las ordenes de un líder, quien, por tal de mantenerse como tal, cambiaba sus ideales. En noviembre de 1910, Ricardo publicó que "el leader tiene que marchar con la masa si no quiere renunciar a la gloria de ser conductor de rebaños". Por su parte, el filósofo, el pensador, el revolucionario libertario no pueden ser leaders porque "van adelante de la masa, piensan más alto que la masa". En cambio, el leader "no es un avanzado: tiene que ser un conservador para que la masa pueda entenderlo y pueda aceptarlo como jefe". El leader, "tiene que ser un perfecto cómico; tiene que fingir creer y desear lo que la vulgaridad desea y cree". Este, no debe ser muy inteligente, si acaso tener "medianía intelectual". Por ello, Bernardo Reyes era charlatán y Madero, un millonario y su intelecto "no alcanza a volar más alto de lo que puede hacerlo un ave de corral". Ricardo, concluyó que "todo leader, en todo tiempo y en todo lugar, dice que encarna las aspiraciones y la voluntad de la masa y es, en efecto, la encarnación de la vulgaridad y la mediocridad de la masa. El leader es el espíritu de las masas". ${ }^{59}$

¿Por qué el leader era una amenaza para la revolución? Porque la expropiación debía ser realizada por todos y para todos, no por la orden de un jefe, sino por el acto de libertad que lleva al individuo a repartirse todo en común, sin autoridades ni leyes. En agosto de 1911 — cuando la historiografía en general ya los ubica derrotados - afirmó Ricardo que en los avances de la lucha anarquista "no se ha necesitado de leaders de 'amigos' de la clase trabajadora, ni han hecho falta 'decretos paternales' 'leyes sabias' ni nada de eso". El pueblo mexicano estaba listo para el comunismo y por ello las expropiaciones que en sus textos - y sólo en sus textos - se realizaban todos los días. ${ }^{60} \mathrm{El}$ comunismo se estaba presentando más rápido de lo imaginado y los líderes no eran necesarios. El pueblo de México era indómito y había iniciado la catástrofe que estaba en marcha, "¡bendita sea!”. ${ }^{61}$ Los indígenas habían despertado en el comunismo y no eran personalistas.

58 Flores Magón, Ricardo, "Para después del triunfo", Regeneración, Los Ángeles, 28 de enero de 1911, p. 2.

59 Flores Magón, Ricardo, , "El espíritu de las masas", Regeneración, Los Ángeles, 20 de noviembre de 1910, p. 2.

60 Flores Magón, Ricardo, "El pueblo mexicano es apto para el comunismo", Regeneración, Los Ángeles, 2 de septiembre de 1911, p. 1.

${ }_{61}$ Flores Magón, Ricardo, "El caos", Regeneración, Los Ángeles, 11 de noviembre de 1911, p. 1. 
Por ello se requería formar conscientes que no siguieran líderes; Regeneración era clave en ello. El ejemplo de los liberales - como se siguen autodenominando a pesar del anarquismo - que no tenían jefes y, por tanto, su papel era realizar la propaganda sobre las expropiaciones que se realizaban de lo que llamaron el movimiento más hermoso de la humanidad. Los jefecillos eran siempre explotadores que desviaban el movimiento con promesas de entregar las tierras mediante reformas agrarias, pero eso era una forma de engañar. Su llamado insistente era "fusilad a vuestros jefes. Ellos os engañan, deliberadamente os engañan, abusando de vuestra buena fe". E indicaban, “tenéis las armas en la mano. ¿Qué esperáis?”, se debía de tomar todo sin hacer caso a los leaders, expropiar y repartir por igual, al grito de " ¡Mueran los jefes! $;$ Viva Tierra y Libertad!". ${ }^{62}$

Así, cuando Emiliano Zapata y Pascual Orozco se rebelaron en 1912 en contra de Madero, aclararon que no eran dichos líderes los que sostenían la lucha, era el movimiento expropiador, era la ira de los desposeídos, la que "iba poniendo la tierra, las provisiones y la maquinaria de producción en poder de los habitantes de las regiones que van visitando, no hacen otra cosa que llevar a cabo un acto de justicia”. Luego preguntaba, ¿cómo ante la evidencia tan clara, había dudas de que en México existía un movimiento esencialmente económico con tendencias al comunismo anárquico $?^{63}$ Estos luchadores conscientes eran la evidencia de que la lucha en México era el Waterloo del capitalismo.

Por ello no se debía pertenecer a la masa, "cada uno de vosotros sea el jefe de sí mismo; que no haya necesidad de que se os empuje a continuar la lucha". La recomendación, en vísperas de ir nuevamente a la cárcel en 1912, era no nombrar jefes, tomar posesión de la tierra y producir libremente. Con ello se lograría la verdadera paz, sin hacer caso a los jefes o leaders que pretendían hacer creer que la autoridad era necesaria. Ante su ausencia no debía suceder lo que, desde su punto de vista, había pasado en su encarcelamiento anterior, en que se enfriaron los ánimos, "sino como trabajadores conscientes, no desmayéis en vuestra actitud en contra del capital y la autoridad". ${ }^{64}$ Por ello, su mensaje era claro, no tener líderes, y por eso ellos no eran "magonistas" ni tenían seguidores, apuntó Enrique, porque los conscientes "tienen bastante dignidad para no lamernos los pies, ni siquiera recibir órdenes nuestras, si alguna vez fuésemos los estúpidos que quisiéramos dárselas". ${ }^{65}$

62 Flores Magón, Ricardo, "Los bribones de Chihuahua", Regeneración, Los Ángeles, 13 de abril de 1912, p. 1.

63 Flores Magón, Ricardo, "Para los que dudan", Regeneración, Los Ángeles, 25 de mayo de 1912, p. 1.

64 Flores Magón, Ricardo, "Los jefes”, Regeneración, Los Ángeles, 15 de junio de 1912, p. 1.

65 Flores Magón, Enrique, "Notas de la rebelión”, Regeneración, Los Ángeles, 11 de mayo de 1912, p. 1. Véase Marco Antonio Samaniego, "El magonismo no existe: Ricardo Flores Magón”, Estudios de Historia Moderna y Contemporánea, núm. 49, 2015, pp. 33-53. 
Antonio de Pío Araujo insistió en llamar al proletariado consciente de Estados Unidos ante la amenaza de la invasión del gobierno yankee. Indicó que el "proletariado consciente se unirá a las fuerzas rebeldes mexicanas y la guerra se extenderá en ambos lados del río Grande". El trabajador mexicano "chocará manos con el trabajador americano y con el negro y todos lucharán contra el enemigo común: el capitalismo internacional". Con ello la revolución social abarcaría "los dos países más importantes del continente" ${ }^{66}$ Los trabajadores inconscientes, al igual que los burgueses y sacerdotes no encontrarían clemencia, "el que no está con nosotros está contra nosotros", indicó De Pío Araujo para luego invocar a los anarquistas que habían asesinado a alguna autoridad conocida: Gaetano Bresci, Angionello, Mateo Morral, libertarios que se multiplicaban en México y que daban el golpe de gracia a Madero y a cualquier otro que deseara gobernar. ${ }^{67}$ Gracias a Regeneración, la masa inconsciente estaba despertando y el proletariado estadounidense se levantaría y se terminaría el capitalismo yankee-mexicano. ${ }^{68}$

En "mueran los leaders", De Pío Araujo indicó que éstos no cumplían con sus promesas, eran falsos y mentirosos, oportunistas que cambiaban de partido como de camisa. Se habían convertido en un problema para el PLM porque con sus falsas promesas distraían la lucha revolucionaria. Querían predominar sobre los demás abogando por la conservación del sistema presente, que era preservar la desigualdad, por lo que eran enemigos de la clase trabajadora. En cambio, el PLM no tenía jefes, no eran magonistas ni seguían ninguna personalidad.

Como trabajadores conscientes, lo mismo que nuestros hermanos, los demás miembros del partido, pensamos con nuestras propias cabezas y nuestros deseos son hacer patente a la clase trabajadora el anacronismo de los "leaders" y los errores en que ha incurrido de que es necesario un jefe o un caudillo que esté al frente para que la conduzca a la victoria. Y esto lo hacemos y seguiremos insistiendo en ello para que la grandiosa revolución no vuelva a encontrar obstáculos en su avance. ${ }^{69}$

${ }^{66}$ De Pío Araujo, Antonio, “AAlto ahí, bandidos!”, Regeneración, Los Ángeles, 17 de agosto de 1912, p. 1.

67 De Pío Araujo, Antonio, "La ley de suspensión de garantías”, Regeneración, Los Ángeles, 24 de agosto de 1912, p. 1. Gaetano Bresci, formado en Paterson, Nueva Jersey, fue el asesino del rey de Italia Humberto I. Michele Angiolillo, anarquista italiano que asesinó en 1896 al presidente del Consejo de Ministros de España, Antonio Cánovas del Castillo. Mateo Morral, anarquista español que intento matar en 1905 y 1906 al rey Alfonso XIII. En 1906, el día de la boda del rey, Morral hizo estallar una bomba, no dañó al rey, pero mató a 25 personas.

68 De Pío Araujo, Antonio, "México y los Estados Unidos", Regeneración, Los Ángeles, 5 de octubre de 1912, p. 1.

69 De Pío Araujo, Antonio, “¡Mueran los leaders!”, Regeneración, Los Ángeles, 12 de octubre de 1912, p. 1. 
La unidad del proletariado tenía el enemigo de la patria, un invento de la burguesía para dividir a los trabajadores. Ante la posibilidad de la invasión yankee, los revolucionarios mexicanos requerían del apoyo del proletariado del mundo, "y especialmente una acción pronta y decisiva de todos los conscientes que radican en los Estados Unidos". Si el proletariado americano y mundial se unían "el capitalismo yankee puede ser barrido en la lucha de clases internacional que se avecina y Norte América quedar emancipado del sistema capitalista". ${ }^{70}$

El asesinato de Madero fue una prueba de que la lucha era contra la autoridad, por lo que Huerta iba a ser masacrado de la misma forma. ${ }^{71}$ El comunismo que se estaba imponiendo gracias a los conscientes, muchos de ellos creados por Regeneración, hacía que la labor expropiadora garantizara el triunfo. En el caso de que comunistas como Zapata - como lo llaman — claudicaran, el pueblo seguiría su lucha. El proletariado consciente no tenía ídolos, no admitía leaders, y el que pretendiera convertirse en uno, "ya sabemos los conscientes el calificativo que debemos aplicarles: ambicioso vulgar". ${ }^{72}$ Con el inicio de la revolución constitucionalista, encabezada por Venustiano Carranza, se llamó a los rebeldes carrancistas a abandonarlo, el movimiento no podía degenerar en un simple movimiento político. Los fusiles debían ser utilizados contra los jefes y oficiales por los buenos soldados de la libertad. Cuando recibieran órdenes de atacar por parte de éstos debían de voltearse y fusilarlos a ellos. Zapata estaba por tomar la ciudad de México, pero si "si llegase a cesar de la obra de expropiación por sugestiones de algún político, evitando de este modo que el pueblo conquiste sus libertades, en este caso no faltara una mano viril que lo ajusticie" ${ }^{73}$ Si bien no creyeron que sucediera, insistieron en que a los jefes se les debía matar.

Antonio de Pío Araujo, en un texto que defiende a Ricardo Flores Magón ante comentarios negativos de la publicación anarquista francesa Les Temps Nevoaux, hizo una relación entre los conscientes y los inconscientes, lo cual nos permite reforzar el objetivo de este escrito. De igual forma, el texto ilustra las complejidades del contingente armado que llegó a Baja California, del cual hemos demostrado en otros escritos no obedecía a Ricardo Flores Magón, por más que existan líneas historiográficas que los llaman "magonistas". Así, quienes iniciaron el movimiento fueron conscientes mexicanos.

70 De Pío Araujo, Antonio, "Frente a la invasión”, Regeneración, Los Ángeles, 26 de octubre de 1912, p. 1.

71 De Pío Araujo, Antonio, "La tiranía de Huerta en abandono", Regeneración, Los Ángeles, 26 de abril de 1913, pp. 1-3.

72 Anónimo, “¡Abajo los Ídolos!”, Regeneración, Los Ángeles, 5 de abril de 1913, p. 1.

73 Por la Junta, "Manifiesto a los rebeldes carrancistas y a los soldados de la libertad", Regeneración, Los Ángeles, 3 de mayo de 1913, p. 1. 
Después llegaron 500 hombres, “en su mayoría conscientes y en minoría inconscientes". Eran de todas las nacionalidades y ante la proclamación de Simón Berthold Chacón de formar una república socialista, los conscientes no estaban de acuerdo, "aunque algunos inconscientes intrigaron constantemente para indefender la península y aun llegaron a ofrecer al que escribe estas líneas la gubernatura". Más tarde, apunta, trataron de formar una república por culpa de un millonario, Dick Ferris, y trataron de apoderarse de la región dominada por los libertarios. ${ }^{74} \mathrm{El}$ argumento de Araujo muestra la diversidad en el contingente armado, y como la dinámica de conscientes/inconscientes debía terminar, Regeneración se mantenía como una publicación para formar revolucionarios conscientes, es decir, expropiadores.

Ante los eventos desatados en la guerra mundial, denunciaron el hambre y la miseria de Europa, por lo que el momento de destruir a la burguesía había llegado. Por ello, estimular, provocar el descontento, "sembrar la rebelión en nuestros corazones es nuestra obligación". ${ }^{75}$ Era el momento de "los que luchamos por los ideales igualitarios sigamos firmes en nuestras aptitudes, inclinaciones y temperamentos, sembrando con la acción o la palabra los ideales redentores que condensa nuestro lema tierra y libertad". ${ }^{76}$ Por ello, apuntó, desde Regeneración lograron sembrar la conciencia de clase en el sur Estados Unidos sin que la versión burguesa predominara y la propaganda de los miembros del PLM, "que ya en partidas de compañeros, o mezclados entre los insurgentes que militan en las filas de los partidos burgueses se sacrifican por sus sacros ideales". ${ }^{77}$

Así, con la ayuda de los "infiltrados" que ya estaban ahí, expropiando, llamaban a los inconscientes, ya que la guerra europea era la gran oportunidad de la conflagración universal, porque "los ilotas muertos de hambre llegarían a convencerse de que no valdría la pena luchar por ninguna patria", sino por la expropiación, única respuesta a los males de la humanidad. ${ }^{78}$ A los inconscientes, llamó Ricardo, para indicarles que luchar para poner una autoridad, como villistas o carrancistas: "el gobierno es vuestro verdugo, quien quiera que sea el gobernante... ¿sabéis acaso de algún gobierno que haya sido bueno para los pobres?”. Y preguntaba, “¿porque no fusiláis a vuestros jefes?”.

74 En los siguientes párrafos de Pío Araujo sostiene la diversidad de actores en el interior del contingente armado.

75 Flores Magón, Ricardo, "La catástrofe mundial”, Regeneración, Los Ángeles, 22 de agosto de 1914.

76 Flores Magón, Ricardo, "Barbas de chivo sobre un volcán”, Regeneración, Los Ángeles, núm. 201, p. 2.

77 Flores Magón, Ricardo, "Para los envidiosos", Regeneración, Los Ángeles, 28 de noviembre de 1914, p. 2.

78 Flores Magón, Enrique, "La miseria y el hambre”, Regeneración, Los Ángeles, 28 de noviembre de 1914 , p. 1. 
Estaban las condiciones de pobreza y miseria, en México y en el mundo, para terminar con la dominación y la injusticia, "al jefe y oficial que se oponga a la expropiación fusiladlo, fusiladlo sin misericordia porque esos son los enemigos de tu clase, los que os embaucan para que los que están arriba sigan explotando y tiranizando a los que están abajo". Así, pues, a tomar el fusil, pero éste es "un instrumento de opresión en manos de un inconsciente, porque sirve para encumbrar tiranos. En manos de un consciente es garantía de libertad y de bienestar". ${ }^{79}$

En 1915 se editaron pocos números de Regeneración; al iniciar 1916 se publicaron los comentarios señalados páginas atrás, el PLM “....se ha esforzado y se esfuerzan por encauzar el movimiento por el sendero del comunismo anárquico". En ninguna parte el lector va a encontrar que se luchaba para hacer una revolución exclusiva en México, y mucho menos por las reformas que se plasmaron en la Constitución de 1917.

¿Era posible formar conscientes desde poblados como Tijuana o Mexicali? ¿Era posible estar relacionado con el mundo y criticar a todos los jefes revolucionarios desde la Ciudad de México? ¿Si el pueblo mexicano, y en especial los indígenas, ya estaban expropiando, desde su punto de vista, desde dónde era posible llamar al pueblo americano y al proletariado europeo? ¿Desde dónde era posible estar en contacto con las publicaciones anarquistas para que éstos se sumaran y reprodujeran que la revolución en México ya era la gran revolución social- económica que estaba terminando con la propiedad privada e implantando el comunismo? Fue Los Ángeles, California, Estados Unidos, desde donde publicaron el llamado a los proletarios del mundo, a pesar de que ser anarquista era motivo de persecución. Su lógica fue ser partícipes de lo que otros ácratas también sostenían, que la conflagración ya estaba en el mundo, una gran revolución social que tocaría España, Italia, Alemania, Rusia y por supuesto, Estados Unidos.

\section{PRECURSORES DE LA REVOLUCIÓN, ¿PERO DE CUÁL? ¿Y LOS INTELECTUALES?}

Un mes más tarde de la muerte de Ricardo Flores Magón el diputado Antonio Díaz Soto y Gama señaló ante el congreso que, a pesar de no ser un reconocido jefe militar, "era el precursor de la revolución, el verdadero autor de ella, el autor intelectual de la revolución mexicana". Él había preparado el camino para que Madero y Carranza lograran la victoria. ${ }^{80}$ En las décadas siguientes

79 Flores Magón, Ricardo, “A los inconscientes”, Regeneración, Los Ángeles, 12 de diciembre de 1914, p. 1.

80 “Antonio Díaz Soto y Gama al congreso de la Unión”, 22 de noviembre de 1922. http://www. antorcha.net/biblioteca_virtual/politica/discursos/3.html. 
esta forma de nombrarlo se volvió tema de diversas polémicas, y su inclusión, tanto en la rotonda de los hombres ilustres en 1944, como en la cámara de diputados en 2000, tuvo discusiones muy ambivalentes. ${ }^{81}$ Finalmente, se impuso una visión en la que Ricardo era el autor del programa del Partido Liberal Mexicano de julio de 1906, es decir, capitalista y reformista. Por su parte, Enrique Flores Magón, además de relacionarse como funcionario con el Estado, llamó constantemente a los precursores de la revolución y se vinculó directamente con Lázaro Cárdenas y Manuel Ávila Camacho. ${ }^{82}$ Fue partícipe directo en construir una imagen de reformista tanto de sí mismo como de Ricardo, es decir, en contra de lo que ambos habían luchado de 1902-1903 hasta cuando menos $1918 .^{83}$

El supuesto "reconocimiento" a Ricardo ha llevado a una descripción común, como la de un intelectual que escribe ideas revolucionarias y da las bases para reformas laborales o el reparto agrario. Una imagen utilizada con frecuencia es retomada de la portada de The Blast (1916), publicación dirigida en San Francisco, California, por Alexander Berkman, anarquista con quien los ácratas del PLM estuvieron en relación directa ${ }^{84}$ En ella Ricardo y Enrique están sentados; Ricardo escribe y Enrique observa al fotógrafo; imagen que tomada por sí sola alimenta la idea de un personaje que tiene ideas revolucionarias: un intelectual que no toma las armas. Así, se ha generado una idea del intelectual de la revolución mexicana, quien con su pluma propuso las reformas sociales de la Constitución de 1917. ${ }^{85}$ Paradójicamente, los anarquistas en general y los del PLM veían a los intelectuales como inútiles, timoratos que no pasaban a la acción revolucionaria.

81 La propuesta para incluir su nombre con letras de oro en la cámara de diputados inició formalmente en 1963 y fue aprobada en vísperas de la salida de Ernesto Zedillo como presidente de México en el año 2000. Concluir que hubo un "reconocimiento" debe ser matizado. Para un comunista-anárquico, ser "reconocido" por diputados y por un programa capitalista es una ironía. Nosotros apuntamos que no es un reconocimiento de los anarquistas del PLM, sino una transformación no sólo del personaje, sino de la lucha del conjunto de los ácratas.

82 Antonio de Pío Araujo, también era empleado de gobierno, aunque hasta el momento no hemos encontrado referencias mayores y todo indica que no se volvió a relacionar con Enrique Flores Magón.

83 Samaniego, Marco Antonio, "Enrique Flores Magón vs Enrique Flores Magón”, Secuencia. Revista de Historia y Ciencias Sociales, Instituto Mora, vol. 49, núm. 159, 2019, pp. 192 218.

84 Berkman es conocido por haber intentado matar en 1892 al empresario acerero Henry Clay Flick, como parte de las acciones anarquistas conocidas como la propaganda por el hecho Berkman, fue pareja sentimental de Emma Goldman. Al salir de la cárcel en 1906 retomó sus actividades anarquistas y tuvo relación directa con los anarquistas del PLM.

85 La portada de la obra de Eduardo Blanquel retoma esta imagen, 2008. 
Para ellos Regeneración no era de intelectuales, sino su manera de participar en la formación de conscientes. Es decir, su acción revolucionaria en Los Ángeles, California, era anunciar los avances continuos de la revolución social en México, expropiadora de la tierra y los medios de producción para promover el contagio en otros países y lograr la revolución en todo el planeta. Paul Avrich, uno de los historiadores del anarquismo más reconocidos, indica que los anarquistas desconfiaban de los intelectuales. Tanto Bakunin como Kropotkin consideraban que los intelectuales debían integrarse a las actividades junto con el pueblo y no ser una casta privilegiada. La desconfianza se centró en la relación de los intelectuales con los políticos. ${ }^{86}$

El 5 de noviembre de 1910 — antes de iniciarse la revolución- Ricardo Flores Magón, al diferenciarse del "ambicioso y vulgar Madero", indicaba que éste tenía "los ideales de la burguesía, esto es, de los ricos, de los intelectuales y de los clérigos" ${ }^{87}$ En abril de 1911 señalaron que el Partido Liberal había demostrado que los movimientos de las clases directoras, "esto es, los intelectuales y los ricos", llevaban al pueblo al matadero porque "los intereses de los intelectuales y los ricos son diametralmente opuestos a los intereses de los trabajadores" ${ }^{88}$ Los mexicanos de la clase baja, sin haber leído a Marx o Kropotkine, sin necesidad de educación, sin saber leer y escribir ni seguir consejos de falsos amigos de los trabajadores iniciaban su camino para gozar del banquete de la vida. Antonio Díaz Soto y Gama, fue llamado "pobre engendro literario", cuando colaboró en 1911 en la formación de la Junta Reorganizadora del Partido Liberal Mexicano para enfrentarse a los anarquistas; fue acusado de ser uno de los intelectuales educados que "garrapatean" en los ejemplares de la publicación homónima. ${ }^{89}$ Los hombres de letras eran los que buscaban cargos o ser electos en el nuevo gobierno, esperando ser candidatos para engañar al pueblo. En cambio, ellos estaban con los expropiadores que avanzaban tomando la tierra y los medios de producción y haciendo a un lado la inútil boleta electoral.${ }^{90}$ Soto y Gama y compañía "eran lombrices intelectuales".

86 Avrich, Paul, Los Anarquistas Rusos, Madrid, Alianza editorial, 1974, pp. 100-106.

87 Flores Magón, Ricardo, "El partido liberal y el partido anti-reeleccionista", Regeneración, Los Ángeles, 5 de noviembre de 1910, p. 1.

88 Flores Magón, Ricardo, "No queremos limosnas", Regeneración, Los Ángeles, 2 de abril de 1911, p. 1.

89 Camilo Arriaga, Jesús Flores Magón, Juan Sarabia, Antonio I. Villareal, formaron la Junta Reorganizadora en la ciudad de México con el fin de retomar el liberalismo inicial. También publicaron Regeneración por varios meses. Jesús Flores Magón ocupó el cargo de secretario de Gobernación al inicio del gobierno de Francisco I. Madero.

$90 \quad$ Flores Magón, Ricardo, “A expropiar”, Regeneración, Los Ángeles, 16 de septiembre de 1911, p. 1. 
Después del enfrentamiento con Luigi Galleani y los anarquistas italianos que llegaron a Tijuana se volvió frecuente ubicar a los "teorizantes del socialismo y el anarquismo" como los culpables de que el proletariado mundial no llegara a apoyar la causa. Los proletarios que estaban expropiando ya se habían dado cuenta de que ningún gobierno era bueno y que durante noventa años de engaños por parte "de la burguesía del dinero y de la intelectualidad"91 luchaban unidos sin necesidad de jefes o leaders. El anarquismo no había surgido en las universidades, era del pueblo y éste era el que expropiaba y esperaba la ayuda de ácratas de todo el mundo, no de los teorizantes como Galleani.

Antonio de Pío Araujo apuntó que hacer leyes y convenciones era perder el tiempo. Los hombres que llenaban la cámara de diputados eran una infinidad de "intelectuales, estadistas, abogados, periodistas, y simples políticos que llenan la cámara de diputados y senadores". ${ }^{92}$ El pueblo debía seguir expropiando como ya lo estaban haciendo para ejemplo del proletariado. Ante la pregunta que les hacían quienes los apoyaban en Estados Unidos sobre quién debía gobernar después de Madero indicaron que "si no fuera por el embrollo de confusiones que en ellos han sembrado los malvados intelectuales y politicastros que se encargan de gobernar la presente sociedad, se ven pues, obligados a hacernos tales preguntas". ${ }^{93}$ Dicho de manera sencilla, al igual que los jefes y leaders que desviaban la verdadera revolución expropiadora, los intelectuales eran también un estorbo. Por ello, el Appeal to Reason, publicación socialista que apoyó su salida de la cárcel en el período de 19071910, sus "intelectuales" que parecían apoyarlos, eran una desilusión. ${ }^{94}$ Incluso, Jean Grave y Enrico Malatesta, anarquistas europeos que no apoyaron a los ácratas del PLM por considerar que no había la revolución económica que se proclamaba en Regeneración, fueran ubicados por Ricardo como intelectuales que dudaban de los avances de los expropiadores. ${ }^{95}$ De igual forma en las críticas que realizaron a la Casa del Obrero Mundial $-\mathrm{y}$ contrario a lo que algunos fundadores indicaron — su publicación, Ariete, deberían escribir "más para el pueblo y un poco menos para los intelectuales, pues encontramos en la revista artículos brillantísimos; pero desgraciadamente, los más hermosos,

91 Flores Magón, Ricardo, “¡Abajo los farsantes!” Regeneración, (Los Ángeles) 9 de marzo de 1912: 1.

92 De Pío Araujo, Antonio, "No hay más que expropiar. Que se hundan los políticos en el corrompido fango de sus crímenes", Regeneración, Los Ángeles, 15 de noviembre de 1912, p. 1.

93 Sin firma, “Conceptos vagos”, Regeneración, Los Ángeles, 15 de noviembre de 1912, p. 2.

94 Owen, William C., "Mexican Notes”, Regeneración, Los Ángeles, 19 de julio de 1913, p: 4.

95 Flores Magón, Ricardo, "La revolución social en Sonora", Regeneración, Los Ángeles, 21 de febrero de 1914, p. 1. Por otra parte, Enrico Malatesta es citado para explicar su estrategia revolucionaria. 
poco inteligibles para las masas populares que es para quien debemos escribir los anarquistas". ${ }^{96}$

Así, los anarquistas del PLM, dedicados a formar conscientes en Los Ángeles, California, no se consideraban intelectuales, pero sí como precursores que veían como se retrasaba el inevitable triunfo de la anarquía por culpa de jefes, leaders, leyes reformistas, sindicatos, intelectuales, que sólo se convertían en obstáculos para lo que de todos modos iba a suceder: el sol de la anarquía sobre todo el mundo. Ellos estaban en la acción, publicando Regeneración, el órgano que mantenía viva la llama que provocaría la caída de los tres monstruos: gobierno, capital y clero.

En las referencias citadas sobre 1916, páginas atrás, destacamos el segundo punto, en el que indican que su publicación "se ha esforzado y se esfuerzan por encauzar el movimiento por el sendero del comunismo anárquico". ¿Por qué encauzar el movimiento revolucionario? Porque éste se había desviado de su final inevitable, porque jefes y leaders, y en menor medida intelectuales, habían desvirtuado lo que ellos iniciaron en 1906. En un discurso titulado "Orientación de la revolución mexicana", en el auditorio Mammoth Hall de Los Ángeles, Ricardo remarcó que la revolución social era una realidad que se debía a las injusticias perpetradas desde que el primer indígena fue atropellado por los españoles y sus tierras confiscadas. La revolución no eran Villa, Carranza o Vázquez Gómez, todos ellos eran la espuma, simples ambiciosos que aspiraban a la presidencia de la República. La revolución era el movimiento del pobre contra el rico, del hambriento contra el harto, del esclavo contra el amo, llevado a efecto por el único medio eficaz "que tiene que el desheredado de todo el mundo para destruir el sistema actual; es este: el fusil, la dinamita y la expropiación". ${ }^{97}$ El Partido Liberal orientaba la revolución hacia el comunismo anárquico y la ayuda debía ser inmediata. Ya estaba colocada la primera piedra del edificio del porvenir y ante el camino avanzado sólo quedaba continuar.

Si bien desde 1911, luego de los eventos en Tijuana, el reclamo a otros ácratas fue continuo, de 1914 en adelante se intensificó. Enrique Flores Magón, en reclamo a la falta de ayuda, resaltó el carácter social de la revolución en México y solicitaba que cuando menos se reconociera que "hay un puñado de hombres (algo así como locos) en Los Ángeles, que se esfuerzan por orientar aquella revolución hacia lo social". Por ello, indicaba que los ácratas debían de apoyar por cualquier medio ya que los libertarios del PLM

96 Flores Magón, Ricardo, “¡Adelante! ¡Adelante!”, Regeneración, Los Ángeles, 6 de noviembre de 1915, p. 1.

${ }_{97}$ Flores Magón, Ricardo, "Orientación de la revolución mexicana", Regeneración, Los Ángeles, 21 de febrero de 1914, p. 1. 
estamos interesados por orientarla hacia el triunfo de las ideas anárquicas comunistas, los que así lo saben por medio de nuestro órgano Regeneración. $\mathrm{Y}$ todos dedicarse concienzudamente, como debe ser, a crear la simpatía obrera mundial para aquel movimiento, y a despertar el espíritu de rebeldía de los proletarios de la tierra dando a conocer los actos justicieros del indio mexicano, para preparar, sino apresurarla, la Revolución Social Universal. ${ }^{98}$

Las ideas académicas sobre la revolución debían quedar de lado y los libertarios tenían que pasar a la acción. Presentarse como los precursores, iniciadores u organizadores, tuvo la intención de demostrar que la revolución social en México era la que abriría la puerta a la participación del proletariado mundial.

En "El deber del revolucionario" Ricardo Flores Magón llamó a los ácratas a cumplir con su obligación y ubica su papel en el despertar de la revolución desde 1892; apuntó que "hicimos todo cuanto pudimos por sacudir al pueblo y volverlo rebelde". Ese espíritu "es el que se muestra hoy lozano y gallardo en México". Los movimientos armados de 1906 y 1908, señaló, fueron preparatorios "para el tremendo movimiento que comenzó el 20 de noviembre de 1910". Si bien el movimiento no inició con un programa comunista anarquista, "nos hemos esforzado y seguiremos esforzándonos por encauzar el movimiento revolucionario hacia el comunismo anárquico". Ricardo ofreció una lista de revolucionarios que desde su punto de vista eran los camaradas que luchaban por el comunismo. Todos deberían seguir el ideal de Malatesta, de iniciar el movimiento y en el transcurso de ésta, con la expropiación, formar conscientes que expandieran la revolución..$^{99}$ Enrique y Ricardo Flores Magón, Anselmo L. Figueroa, Librado Rivera y Antonio de Pío Araujo, llevaban el mensaje a todos los rincones de México donde los expropiadores tomaban la tierra y los medios de producción para repartirlos en común. Ellos llegarían hasta el fin: el aniquilamiento del sistema capitalista. Los apóstoles, en sus escritos, eran los miles de hombres que se mezclaban con los grupos armados o que iban por ciudades, villas, pueblos y rancherías, contribuyendo a encauzar la aspiración popular hacia la organización "de una sociedad sin ricos, sin autoridades y sin sacerdotes". ${ }^{100}$

El progreso de la revolución económica en México se debía a ellos, por lo que estaban satisfechos, "la semilla sembrada por nosotros no fue depositada en tierra ingrata. Las ideas anarquistas se han abierto paso en 
México y se agitan en los cráneos de los desheredados". El movimiento, de manera clara, se orientaba al comunismo anárquico. Los sacrificios realizados por los miembros del PLM no habían sido estériles. ${ }^{101}$ La revolución social había surgido en 1906, y "el movimiento revolucionario actual, no es más que una continuación del movimiento iniciado en Jiménez y Acayucan". ${ }^{102}$ Ante el embate de las autoridades estadounidenses en contra de socialistas y anarquistas, seguros de que serían encarcelados nuevamente, Ricardo afirmó: "la semilla está sembrada. Vamos tranquilos al sacrificio, con la seguridad de que la semilla que con profusión hemos regado tendrá que germinar". La idea "es libre y continuará iluminando consciencias, tocando corazones, sacudiendo dignidades y despertando las dormidas cóleras, madres formidables de la barricada y de la guillotina". ${ }^{103}$

\section{LA GRAN REVOLUCIÓN SOCIAL EN MÉXICO Y EN EL MUNDO}

La narrativa planteada en Regeneración proclamó la historia de persecuciones, sobre todo para el caso de Ricardo, desde 1892, para demostrar su legitimidad de reorientar la revolución hacia el resultado último e inevitable: la anarquía. Sin embargo, en la transformación de su lucha anarquista a una supuesta lucha capitalista, que inició luego de la muerte de Ricardo y a lo que se sumó Enrique en los años siguientes, se ha realizado simplificación con respecto a la revolución encabezada por Madero. La de éste fue una revolución política, la de los anarquistas del PLM, o "los magonistas" — que es parte del equívoco- fue una revolución social. Los autores que tocan el tema centran la diferencia en los enfrentamientos en Chihuahua, entre Francisco I. Madero y Prisciliano G. Silva, en el cual este último fue encarcelado. Previamente, Lázaro Gutiérrez de Lara, decidió combatir con Madero y facilitar la captura de Silva. Ricardo publicó el texto "Francisco I. Madero es un traidor a la causa de la libertad" y supuestamente, se generó una ruptura. ${ }^{104}$ Cabe señalar que Silva posteriormente se unió a la causa de Madero.

101 Flores Magón, Ricardo, “¡Alto ahí!”, Regeneración, Los Ángeles, 4 de diciembre de 1915, pp. 1-2. Esta centralidad apuntada, se debe a los conflictos con otros anarquistas que consideraban que era falso que el movimiento revolucionario tuviera el carácter anárquico que se señala en Regeneración.

102 Marquina, Celso, “Carranza traiciona la revolución”, Regeneración, Los Ángeles, 22 de abril de 1916, p. 1. Celso Marquina es un seudónimo utilizado por Ricardo Flores Magón. Es posible que, para tratar de evadir la persecución de las autoridades estadounidenses, por su anarquismo, decidiera usar este seudónimo, como había sucedido en años anteriores.

103 Flores Magón, Ricardo, "Nuestro proceso", Regeneración, Los Ángeles, 21 de abril de 1917, p. 1.

104 Flores Magón, Ricardo, "Francisco I. Madero es un traidor a la causa de la libertad", Regeneración, Los Ángeles, 25 de febrero de 1911, p. 1. 
Es importante destacar que la referencia a la revolución social es propia del comunismo anárquico y hace referencia a la gran revolución que se va a presentar en todo el mundo. Ubicarla como social, tanto en Europa como en Rusia, era para indicar que no se luchaba para imponer a un gobernante, sino para que nadie estuviera en el poder. Luchar para nombrar gobernantes no era la lucha del proletariado. ${ }^{105}$ La única revolución que liberaría al pueblo, escribió Bakunin, era la total, universal, caótica, primitiva y sin límites de ninguna clase. Como apuntaron en Regeneración, del caos surgiría un nuevo orden, sin políticos, funcionarios y clero.

En Regeneración, desde 1904, se publicaron referencias al anarquismo, aunque siempre indicaban que su bandera, luego de 1906, era el Programa del Partido Liberal Mexicano. ${ }^{106}$ A finales de 1910 se publicaban varias líneas revolucionarias: panamericanistas, sindicalistas, socialistas y algunas claramente ácratas. Sin embargo, desde octubre de 1910 Ricardo ponderó los movimientos de 1906 y 1908 como un llamado a tomar posesión de la tierra que le pertenecía a la humanidad entera, y que "por el sólo hecho de vivir tienen derecho a aprovechar en común por medio del trabajo toda la riqueza que la tierra es capaz de producir". ${ }^{107}$ En el mismo número se llamó a los mexicanos a apoyar a los trabajadores estadounidenses sin distinguir nacionalidad, dado que lo relevante era ser proletarios. Posteriormente, el 5 de noviembre, al referirse a Madero, ubicarlo como burgués, sin relación con el proletariado, ligado a intelectuales y a los ricos, fue la pauta para señalar que había dos caminos sin relación alguna: "sus tendencias son diametralmente distintas a las tendencias del partido liberal. El partido antirreeleccionista es un verdadero partido conservador". ${ }^{108}$

Sin embargo, el 3 de enero de 1911, en las instrucciones generales para los revolucionarios, la junta señaló que luchaban por el PPLM de julio de 1906 y en contra de los capitalistas y los tiranos. En el punto número 11, indicaron:

Para evitar choques con las fuerzas maderistas, los grupos liberales deberán tratar con toda corrección a los grupos maderistas tratando de atraerlos bajo la bandera liberal. La causa del Partido Liberal es distinta a la causa maderista por ser la liberal la causa de los pobres; pero en cada caso dado, ya sea para le resistencia como para el ataque, pueden combinarse ambas fuerzas y permanecer combinadas por el tiempo que dure tal necesidad. ${ }^{109}$

Avrich, 15, 26, 30, 33.

Samaniego, "En contra", pp. 1-36.

Flores Magón, Ricardo, “Tierra”, Regeneración, Los Ángeles, 1 de octubre de 1910, p. 1.

Flores Magón, Ricardo, "El Partido liberal y el Anti-Reeleccionista”, Regeneración, Los Ángeles, 5 de noviembre de 1910, p. 1.

La junta, "Instrucciones generales a los revolucionarios", Regeneración, Los Ángeles, 7 de enero de 1911 , p. 2. 
Esta afirmación ha dado pie a que se interprete como una supuesta unión con el maderismo, cuando en realidad sostiene que sólo sería cuando la necesidad lo impusiera. Tres semanas después, el 28 de enero de 1911, —un día antes que iniciara el movimiento armado en el Distrito Norte de la Baja Californiaindicaban su propuesta: "no confiemos en ningún gobierno la solución de nuestros problemas. Los gobiernos son los representantes del capital y, por lo mismo, tienen que oprimir al proletariado". ${ }^{110}$

Por ello, mostrar sus sacrificios al pueblo estadounidense y a los anarquistas de cualquier nacionalidad en Estados Unidos y en Europa, así como haber sido quienes habían empezado la lucha era de relevancia para su causa revolucionaria: sin propiedad privada, todo para todos; sin patria ni banderas nacionales, sin distinciones entre los trabajadores de todo el mundo. Los conscientes estaban con el PLM, los inconscientes con Madero. De esta forma indicaron que la revolución política era de Madero; y la de ellos, social. Bajo esta óptica, de manera equívoca numerosos autores interpretan que las demandas sociales de la revolución eran las de los anarquistas del PLM, sin embargo, éstos utilizaban el término no para las reformas que se les atribuyen, sino para indicar que era una revolución social en México, pero en términos de las expropiaciones que se realizaban, no de las reformas que ellos consideraban inútiles: huelgas, salarios, ocho horas diarias de labor, indemnizaciones, reparto agrario controlado por el Estado. La revolución social a la que se referían es lo que se repitió cientos de veces: las expropiaciones se estaban realizando y era un proceso que no se detendría hasta que el pueblo terminara con toda autoridad y el movimiento se tornara mundial. La prueba a que hicieron referencia eran los cambios de gobierno, los cuales culminarían con la desaparición del Estado y del capitalismo.

Mencionar su acción en contra de Díaz fue con la intención de orientar un movimiento del que Madero estaba recogiendo los frutos mediante el engaño, además de los jefes y leaders que no expropiaban. En mayo de 1911, luego de la ocupación de Tijuana, afirmaron que el poblado ya vivía en el anarquismo y así lo publicaron en Tierra y Libertad, de Barcelona, L'Era Nuova, de Paterson, Nueva Jersey, Cronaca Sovversiva, de Barre, Vermont, Les Temps Nouveaux y Le Libertaire, de París, Francia. De igual forma, en Cultura Proletaria y Cultura Obrera, editada en Nueva York. En esas fechas llegaron alrededor de 50 ácratas de varias partes de Estados Unidos para educar a los hombres que ocupaban el poblado en el anarquismo. Sin embargo, lejos de ese resultado, el grupo calificó al movimiento como da tavolino, de mesita, inventado en las páginas de Regeneración. ${ }^{111}$ En los años siguientes, ante los anarquistas,

110 Flores Magón, Ricardo, "Para después del triunfo", Regeneración, Los Ángeles, 28 de enero de 1911, p. 2.

111 Samaniego, Marco Antonio, 2017, pp. 1137-1138. 
insistieron en la revolución expropiadora iniciada por ellos, misma que, con la ayuda del proletariado, se tornaría mundial.

\section{Conclusiones}

Los anarquistas del Partido Liberal Mexicano han sido encuadrados en la revolución mexicana como precursores de ella, centrando la atención en Ricardo. Lo que se ha designado como "reconocimiento" es en realidad una transformación de la lucha de un grupo por terminar con el capitalismo, el Estado, la propiedad privada y cualquier forma de creencia religiosa. A cambio se les ubica como reformistas, socialistas, anarcosindicalistas, y aunque se menciona el anarquismo, no se le ubica en su vertiente del comunismo anárquico. Su actividad en Los Ángeles, California, ha sido explicada sólo en términos de que quedaron fuera del movimiento armado, sin formar parte de los grupos revolucionarios, alejados de aquéllos en los que pudieran influir con las reformas sociales, consideradas por ellos como inútiles.

Los epítetos en contra de Ricardo son numerosos, diversos autores ubican su nombre como centro para luego colocarlo fuera de la realidad, "irracional", apunta Eduardo Blanquel; "miedoso" señala Lawrence Taylor; "incapaz", escribe Blaisdell; "fracasado" apuntan Albro y Lomnitz. Junto a ello, aparecen los términos de visionario, soñador, utopista, revolucionario incansable y muchos otros. El de precursor, oficializado, lo ubica con un programa contrario a la lucha anarquista y lo lleva al congreso, con letras de oro, luego de muchos años en los que se discutió el tema.

En el presente escrito ubicamos a los anarquistas del Partido Liberal Mexicano en el contexto de su verdadera lucha: la revolución mundial. Los Ángeles, California, Estados Unidos, fue el lugar que escogieron para llevar su mensaje, llamaron al pueblo estadounidense, a los anarquistas europeos, e indicaron que los expropiadores ya estaban avanzando en todo México practicando el comunismo, tomando la tierra y los medios de producción para beneficio de todos. Primero en Baja California y luego en todo México había tierras para quienes llegaran a luchar: "México es suficiente (sic) extenso para sostener a todos los habitantes de Europa. No hay que temer a que falte la tierra para el natural ni para el que ofreció generosamente su sangre, ni tampoco para el que busque una sociedad solidaria y libre... ;Y que revolución más grande harían los obreros si dejaran Europa para los burgueses y fueran a fundar sus hogares en la tierra libre de México!". ${ }^{112}$

112 Un libertario, "La leva revolucionaria”, Regeneración, Los Ángeles, 25 de abril de 1914, p. 2. 
La primera piedra estaba puesta, si cada uno se mantenía en su puesto el triunfo del anarquismo era seguro. Afirmaron que en todo México estaba el caos revolucionario que liberaría de la opresión a millones de seres. Regeneración era el paladín que, "más acá de la frontera mexicana", llevaba el mensaje de la expropiación para llamar al mundo proletario unirse en contra de cualquier gobierno. La semilla estaba sembrada para que se continuara la lucha sin jefes o leaders, con los expropiadores tomándolo todo y trabajando en común. La burguesía, "con su estupidez, había colaborado en su destrucción por sus excesos". Era el momento de unirse todos a la lucha. Poco después, desde el gobierno y con ayuda de varios de ellos (Enrique Flores Magón, Antonio de Pío Araujo o el "loco" de Antonio Díaz Soto y Gama) se ubicaron en la revolución mexicana y transformaron la historia de un colectivo como los primeros, los precursores, y "reconocieron" a Ricardo, sentados a su lado, para reconocerse a sí mismos y disputar la memoria social.

\section{REFERENCIAS}

Abad de Santillán, Diego, Ricardo Flores Magón. Apóstol de la revolución mexicana, Ciudad de México, Grupo Cultural Ricardo Flores Magón, 1925.

Albro, Ward S., Always a rebel: Ricardo Flores Magón and the Mexican revolution, Forth Worth, Texan Christian University Press, 1992.

Anaya, Pedro María, Precursores de la Revolución Mexicana, Ciudad de México: Secretaría de Educación Pública, 1955.

“Antonio Díaz Soto y Gama al congreso de la Unión”, 22 de noviembre de 1922. http:// www.antorcha.net/biblioteca_virtual/politica/discursos/3.html.

Archivo electrónico Ricardo Flores Magón, http://archivomagon.net/obras-completas/ correspondencia-1899-1922/c-1911/cor325/ [consultado el 10 de junio de 2020].

Avrich, Paul, Los Anarquistas Rusos, Madrid, Alianza editorial, 1974.

Barrera Fuentes, Florencio, Historia de la Revolución Mexicana. La etapa precursora, Ciudad de México, Instituto Nacional de Estudios Históricos de la Revolución Mexicana, 1955.

Bartra Armando-Jacinto Barrera. La revolución magonista (cronología narrativa). www.brigadaparaleerenlibertad.com, 2018.

Bartra, Armando, "Introducción", Regeneración. 1900-1918. La corriente más radical de la revolución mexicana de 1910 a través de su periódico de combate. Ciudad de México: Editorial Era, 5a. edición, 1985.

Blaisdell, Lowell, The Desert Revolution. Baja California, 1911, The University of Wisconsin Press, 1962.

Blanquel, Eduardo, Ricardo Flores Magón y la Revolución mexicana, y otros ensayos, prólogo, selección y edición de Josefina MacGregor, México, El Colegio de México, 2008. 
Cámara de Diputados del H. Congreso de la Unión, LIX legislatura, Colección Muro de Honor, 133. http://www.diputados.gob.mx/LeyesBiblio/muro/pdf/floresm. pdf, 2000.

Carrillo, Rafael, Ricardo Flores Magón. Esbozo biográfico (s.1.), 1945.

Duffy Turner, Ethel, Ricardo Flores Magón y el Partido Liberal Mexicano, Morelia, Michoacán, Editorial Erandi, 1960.

Gill, Mario, "Turner, Flores Magón y los filibusteros", Historia Mexicana, vol. 4, núm. $5,1956$.

González Monroy, Javier, Ricardo Flores Magón y su actitud en Baja California, México, Editorial Academia Literaria, 1962.

Kaplan, Samuel, Peleamos contra la injusticia. Enrique Flores Magón, precursor de la revolución mexicana cuenta su historia, México, Libro Mex, Editores, 1960.

Lomnitz, Claudio, El regreso del camarada Ricardo Flores Magón, México, Ediciones Era, 2016.

Samaniego, Marco Antonio, Nacionalismo y Revolución. Los acontecimientos de 1911 en Baja California. Tijuana, Baja California: Universidad Autónoma de Baja California-Consejo Nacional para la Cultura y las Artes- Centro Cultural Tijuana, 2008.

Samaniego, Marco Antonio, "El magonismo no existe": Ricardo Flores Magón", Estudios de Historia Moderna y Contemporánea, núm. 49, 2015. DOI: https:// doi.org/10.1016/j.ehmcm.2014.12.001

, "El poblado fronterizo de Tijuana, Emiliano Zapata y la revoluzione da tavolino", Historia Mexicana, vol. LXVI, núm. 3, 2017.

, "En contra del programa del Partido Liberal Mexicano: los anarquistas del PLM”, Secuencia. Revista de historia y ciencias sociales, núm. 107, 2020.

, “Enrique Flores Magón vs Enrique Flores Magón”, Relaciones. Estudios de Historia y Sociedad, vol. 40, núm. 59, 2019.

, "Las estrategias de los anarquistas del Partido Liberal Mexicano. Modificaciones en el entorno estadounidense y revolucionario, 1902-1918", Estudios de Historia Moderna y Contemporánea de México, núm. 58, 2019.

Taylor, Lawrence, La campaña magonista de 1911 en Baja California. Tijuana, Baja California, El Colegio de la Frontera Norte, 1991.

Torres, Javier, La revolución sin frontera. El partido Liberal Mexicano y las relaciones entre el movimiento obrero de México y el de Estados Unidos. 1900-1923, Ciudad de México, Facultad de Filosofía y Letras, Universidad Nacional Autónoma de México, ediciones Hispánicas, 1990.

\section{Prensa}

Regeneración, Los Ángeles, California, 1910-1918.

Tierra y Libertad, Barcelona, España, 1911.

Cultura Proletaria, Nueva York, Estados Unidos, 1910-1911.

Cultura Obrera, Nueva York, Estados Unidos, 1911-1918. 


\title{
La derecha mexicana en los años veinte: tradición católica y conservadurismo
}

\author{
Javier Mac Gregor Campuzano*
}

Recibido: 27 de diciembre de 2019

Dictaminado: 22 de abril de 2020

Aceptado: 21 de agosto de 2020

\section{RESUMEN}

El artículo estudia la forma en que se organizó, en la década de 1920, la corriente política mexicana caracterizada como de derecha, bajo distintas denominaciones, centrándose en las agrupaciones que, desde finales de la década anterior, participaban en los distintos niveles de la vida política nacional: electoral, parlamentario, territorial, etcétera. En este panorama, llama la atención la aparición de múltiples personajes (Palomar y Vizcarra, Capistrán Garza, Diego Arenas Guzmán, Rafael Ceniceros y otros), que con diversa intensidad participaron en las organizaciones de derecha hasta conformar la Liga Nacional de Defensa de la Libertad Religiosa, la cual estalló la guerra en contra del Estado mexicano hacia mediados de 1926 hasta concluir en los arreglos de junio de 1929. El artículo se sustenta en la bibliografía más actualizada sobre el tema, así como en un conjunto de fuentes primarias de enorme utilidad.

Palabras clave: política, partidos, derecha, conservadurismo, politicos. 


\title{
The mexican political right in the twenties: Catholic tradition and conservatism
}

\begin{abstract}
The article studies de way in which the political current called "the right wing", organized in Mexico under different denominations all along the second decade of the XXth. Century. This analysis enfatizes the organizations that participated in the national political life at different levels: in election, in the Congress, in the territorial movements, etc. The interesenting thing in this landscape is the presence of some political actors (Palomar y Vizcarra, Capistrán Garza, Rafael Ceniceros, Diego Arenas Guzmán, etc.) who appears with different degrees in this organizations, which will flow in the National League for the Defense of the Religious Freedom. This will declare war to the Mexican State since 1926 till mid-1929, when the "arrengments" were obtained. This work is based in the main bibliography on the subject, and also uses some primarial sources of great interest and utility.
\end{abstract}

Key words: politics, parties, right wing, conservatism, politicians.

\section{INTRODUCCIÓN}

La ilusión de que no existe se debe a que la derecha en México no se encuentra solo - ni siquiera principalmente - a la derecha del poder central del 'gobierno de la Revolución mexicana'. La derecha está simultáneamente en el poder y en la oposición, en el gobierno y en la sociedad. Roger Bartra, Viaje al centro de la derecha, p. 52.

\footnotetext{
Caracterizar a una corriente política del México de la década de 1920 como de derecha sería sencillo si el esquema dicotómico tuviera algún sentido para explicar la geografía de la política durante aquellos años. Pero no lo tiene. A la afirmación recurrente de que sólo los "revolucionarios" podían ser parte de los círculos del poder de la nueva élite política formada a partir del triunfo de la Revolución de 1910, pero consolidada durante la década siguiente, se oponía la acción de grupos y movimientos que pugnaban por ampliar su papel, y, en el caso de los sectores más conservadores, por combatir y modificar el
} 
rumbo político del país, que tenía como faro institucional a la Constitución firmada en Querétaro en febrero de 1917. Sin embargo, concuerdo con Bartra en que la dicotomía entre revolucionarios y reaccionarios, nosotros y ellos, es una imagen discursiva falsa, que sólo tiene pretensiones legitimadoras y no encuentra correspondencia con la realidad de esos años; es más, a menudo choca con ésta.

La presencia de los miembros de la familia revolucionaria, como se autocaracterizaban, con intereses económicos cada vez más definidos y extensos, o con ambiciones políticas que no podían ser canalizadas a través de los medios formales de participación en la arena política institucional (no había cargos relevantes para todos), generó manifestaciones frecuentes de descontento, principalmente militares: los generales Mario Ferrer, Miguel Alemán, Juan Carrasco, Cástulo Pérez, Guadalupe Sánchez, Arnulfo Gómez y muchos otros, pese a su formal adscripción al grupo de los revolucionarios, en realidad representaban los intereses de la estirpe más conservadora y luchaban - muchas veces, llegando a morir- contra el régimen.

En general, la izquierda, principalmente comunista o anarquista, no significó una preocupación seria para el gobierno revolucionario durante esta década, en lo que se refiere a la búsqueda del poder político o a un serio trastrocamiento del orden constitucional (no me refiero aquí a su importancia en la organización de movimientos campesinos o a su papel en la organización obrera).

La promulgación de la Constitución en 1917, con su enorme significado por la incorporación de derechos sociales e individuales, generó una reacción inmediata entre los sectores conservadores, en particular los vinculados con la jerarquía católica, pues tales derechos afectaban directamente a sus intereses. De acuerdo con Carmen Collado, "el anticlericalismo revolucionario se expresó a través de la separación completa de la Iglesia y el Estado", y esto generó una clara disputa por la lealtad de los ciudadanos. ${ }^{1}$

Pero la tensión, naturalmente, no apareció de manera súbita el 5 de febrero de 1917, sino que se venía gestando desde mucho antes. No viene al caso remontarnos al siglo XIX para explicar los efectos que tanto las Leyes de Reforma como la Constitución de 1857 tuvieron sobre estas relaciones, pero cabe mencionar que se pudo establecer entre el régimen porfirista y la Iglesia un estado de "conciliación", el cual fue sacudido violentamente por el estallido revolucionario en 1910, caracterizado — como han visto algunos autores - por un "anticlericalismo radical". Esto, una vez resuelta la fase armada entre los partidarios de la Convención y los constitucionalistas, a favor de los últimos, quedó marcado en el texto constitucional: 
El artículo $3^{\circ}$, relativo a la educación, impide la participación del clero en la instrucción primaria y secundaria, así como la destinada a normalistas, obreros y campesinos. El artículo $5^{\circ}$ prohíbe el establecimiento de órdenes monásticas. El 24 prohíbe los actos religiosos fuera de los templos. El 27 impide a las Iglesias la adquisición, posesión y administración de bienes raíces y el 130 no reconoce personalidad jurídica 'a las agrupaciones denominadas iglesias', y restringe absolutamente las actividades sociales y políticas de los ministros de cultos. ${ }^{2}$

Éste fue el punto central del choque permanente. Como menciona Roberto Blancarte, "en el terreno político, la vigencia o transformación de los artículos constitucionales se convierte en el punto esencial del conflicto entre Iglesia y Estado". ${ }^{3}$

La visualización y el análisis de esta tensión, sin embargo, se complejiza cuando aparecen actores que, sin ser propiamente adversarios activos al marco constitucional, devienen opositores al orden establecido por la familia revolucionaria - a la cual, en algún momento, pudieron estar integrados-, y que, por lo mismo, son caracterizados como reaccionarios, como fue el caso de Luis Cabrera y José Vasconcelos (o de Juan Sánchez Azcona y Diego Arenas Guzmán, a quienes estudiaré aquí): “aunque la Revolución los consideró reaccionarios, sus críticas no corresponden [al menos durante la década de 1920] a lo que se podría considerar un verdadero proyecto conservador, reaccionario o, propiamente, de 'derecha"'. ${ }^{4}$

El objetivo de este artículo es mostrar la forma en la que se constituyeron las más importantes organizaciones de derecha de nuestro país, para influir de manera significativa en la definición del rumbo político del mismo. El principal eje del análisis consiste en el seguimiento de la actuación de determinados personajes que aparecen recurrentemente en la integración y actuación de las agrupaciones. Para ello, parto de la idea desarrollada por Soledad Loaeza (basada en Ernest Nolte) de que la derecha siempre surge como una respuesta política - en este caso, al régimen revolucionario y a los principios establecidos por el constituyente de 1917—, y que esto le imprime un carácter defensivo. Sin embargo, continúa Loaeza, "en situaciones críticas [esta derecha] asume estrategias de ataque [...] y desarrolla cierta autonomía que se expresa en proyectos políticos aparentemente constructivos". 51

Blancarte, "Modernidad", p. 155.

Ibid., p. 157.

Barrón, "Conservadores", p. 438. En su momento, Vasconcelos - como no podía ser de otra manera - comentaba inteligentemente a principios de 1929: "me llaman reaccionario aquellos mismos que de la Revolución han sacado los latifundios y los palacios". Ibíd., p. 450 .

5 Loaeza, "Conservar", p. 31. Por ejemplo, Jean Meyer señala que la Liga de Defensa de la Libertad Religiosa nació como una reacción de defensa, se convirtió en un movimiento 
análisis que aquí presento cruza toda la década de 1920, pues abarca desde el inicio de la institucionalización sonorense, en ese año, hasta la conclusión de la Guerra Cristera mediante los arreglos de 1929, momento a partir del cual esta oposición comienza una nueva etapa.

Sin duda, el caso mexicano fue peculiar en el contexto político latinoamericano de la tercera década del siglo xx, pues el fenómeno de la Revolución mexicana cruzó y marcó profundamente la conformación y el desarrollo de todo el proceso político nacional. ${ }^{6}$ La Constitución de 1917 se convirtió en el referente político fundamental para el entramado de todos los aspectos económicos, judiciales, sociales e institucionales del país. A través de las normas, a decir de Pedro Salazar, los juristas se propusieron transformar la convivencia; sin embargo, enfatiza el autor, las normas, más que el mero marco de nuestra convivencia, son su molde. De esta forma, "las constituciones postulan los principios que dan identidad al Estado que las adopta". ${ }^{7}$ En este caso, como una república representativa, democrática y federal.

Según veíamos en párrafos anteriores, en México se establecieron una serie de principios normativos tendientes a regular tanto las relaciones entre la Iglesia y el Estado, como la influencia de aquélla sobre el conjunto social. Esto, sumado a lo que se consideraba — desde la época del constitucionalismo- como una política persecutoria contra la jerarquía, generó continuas manifestaciones de rechazo por parte de la Iglesia como institución y de muchos de sus feligreses. El reto no era menor. Dos autores clarifican el tamaño del desafío para el Estado que se encontraba, primero, en pleno proceso de reconstitución y, luego, de institucionalización política plena. Roberto Blancarte reflexiona sobre el aspecto que mayor preocupación podía generar a los estadistas del régimen revolucionario: "la iglesia católica en México cuenta [entonces] con una doctrina social que se constituye en un modelo alternativo de organización social y con los elementos materiales, pero sobre todo humanos, que le permitirán hacer frente a las embestidas del régimen a lo largo del siglo Xx". ${ }^{8}$ A esta idea, Marta Eugenia García Ugarte agrega cómo la nueva clase política — pero particularmente Calles — visualizaba esta amenaza:

Calles consideraba a los católicos como un grupo político con raíces profundas en la nación mexicana. Se trataba de una fuerza política real que si lograba articular sus demandas de tipo religioso con las demandas políticas de los revolucionarios

político y "pasó de la defensiva a la ofensiva con la firme intención de tomar el poder y ejercerlo por entero". Meyer, La cristiada 1, p. 50.

6 Acerca de la particularidad del caso mexicano en el contexto iberoamericano, véase Lida, Bohoslavsky y Jorge, Las derechas.

Salazar, "Longeva", p. 4.

Blancarte, "Modernidad", p. 155. Cursivas mías. 